\title{
Evolution of GLM-Observed Total Lightning in Hurricane Maria (2017) during the Period of Maximum Intensity 0
}

\author{
AlEXANDRE O. FierRo \\ Cooperative Institute for Mesoscale Meteorological Studies, University of Oklahoma, and NOAA/OAR/National Severe Storms \\ Laboratory, Norman, Oklahoma \\ STEPHANIE N. STEVENSON \\ Cooperative Institute for Research in the Atmosphere, Colorado State University, Fort Collins, Colorado, and NOAA/National \\ Hurricane Center, Miami, Florida \\ ROBERT M. RABIN \\ NOAA/OAR/National Severe Storms Laboratory, Norman, Oklahoma
}

(Manuscript received 20 February 2018, in final form 21 March 2018)

\begin{abstract}
Total lightning data obtained from the Geostationary Lightning Mapper (GLM) were analyzed to present a first glimpse of relationships with intensity variations and convective evolution in Hurricane Maria (2017). The GLM has made it possible, for the first time, to analyze total lightning within a major hurricane for a long period, far from ground-based detection networks. It is hoped that these observations could enlighten some of the complex relationships existing between intensity fluctuations and the distribution of electrified convection in these systems.

Prior to rapidly intensifying from a category 1 to category 5 storm, Maria produced few inner-core flashes. Increases in total lightning in the inner core $(r \leq 100 \mathrm{~km})$ occurred during both the beginning and end of an intensification cycle, while lightning increases in the outer region $(100<r \leq 500 \mathrm{~km})$ occurred earlier in the intensification cycle and during weakening. Throughout the analysis period, the largest lightning rates in the outer region were consistently located in the southeastern quadrant, a pattern consistent with modeling studies of electrification within hurricanes. Lightning in the inner core was generally tightly clustered within a $50-\mathrm{km}$ radius from the center and most often found in the southeastern portion of the eyewall, which is atypical. Bootstrapped correlation statistics revealed that the most robust and systematic relationship with storm intensity was obtained for inner-core lightning and maximum surface wind speed. A brief comparison between flash rates from GLM and a very low-frequency ground-based network revealed that not all lightning peaks are seen equally, with hourly flash-rate ratios between both systems sometimes exceeding two orders of magnitude.
\end{abstract}

\section{Introduction}

At low to midlatitudes, tropical cyclones (TCs) cause considerable loss of life and property around the globe annually. Coastal communities and the shipping industry are particularly vulnerable to the hazards posed

Supplemental information related to this paper is available at the Journals Online website: https://doi.org/10.1175/MWR-D-180066.s1.

Corresponding author: Alexandre O. Fierro, alex.fierro@noaa. gov by TCs. While track forecast errors have greatly improved over the last decades, TC intensity predictions have improved at only about half the rate of track forecasts (Marks and Shay 1998; Kaplan et al. 2015; DeMaria et al. 2014). This is because the intensity fluctuations of a TC chiefly rely on cloud-scale, hard-to-forecast stochastic processes taking place within the inner core of the TC (e.g., Anthes 2003; Hendricks et al. 2004; Montgomery et al. 2006; Nolan et al. 2007; Guimond et al. 2010; Smith and Montgomery 2015; Hazelton et al. 2017; Wadler et al. 2018). Most active observing platforms (ground-based or hurricane hunter aircraft) and polar orbiting satellites do not provide continuous 
coverage of cloud-scale properties of TCs, since these systems develop and intensify over open oceans. The lack of a systematic availability of critical observations, coupled with our incomplete understanding of the small-scale physical processes leading to TC intensification, imposes an inherent limit to their predictability (e.g., Zhang and Sippel 2009).

To fill this gap, many have proposed that another data source-lightning_could be utilized to supplement available datasets to augment our ability to better predict hurricane intensity changes through an improved representation of their convective state. The recent successful launch of the Geostationary Lightning Mapper (GLM; Goodman et al. 2013) on board the Geostationary Operational Environmental Satellite 16 (GOES-16; Gurka et al. 2006) provides researchers and forecasters an unprecedented opportunity to analyze continuous coverage of total lightning data [i.e., cloudto-ground (CG) plus intracloud (IC) flashes] associated with high-impact weather (including TCs) near and over the Americas. Total lightning is emphasized here, given that, in contrast to ground flashes, these were shown to better correlate with bulk storm quantities, such as graupel/hail volume, updraft volume, and maximum vertical velocity (e.g., Goodman et al. 1988; MacGorman et al. 1989; MacGorman and Rust 1998; Carey and Rutledge 1996; Lang and Rutledge 2002; Wiens et al. 2005; Kuhlman et al. 2006; Fierro et al. 2006). An example of the application of total lightning data toward the forecast of high-impact weather events is best illustrated by the lightning jump algorithm, which was shown to precede the occurrence of severe weather events, including tornadoes (e.g., Schultz et al. 2011; Chronis et al. 2015). Explicit cloud-scale numerical simulations of the electrification processes within TCs also revealed robust relationships between total lightning and graupel/updraft volume within both the inner core and outer region (Fierro et al. 2015; Fierro and Mansell 2017, 2018).

Past observational studies focusing on lightning within TCs primarily utilized CG flash data detected by global, long-range, very low-frequency (VLF) ground-based networks, such as the World Wide Lightning Location Network (WWLLN; Jacobson et al. 2006) or the Väisälä Global Lightning Detection Network (GLD360; Said et al. 2010; Holle et al. 2016). Although these works paved the way toward our understanding of the general patterns, evolution, and morphologies of lightning within TCs, the low detection efficiency of VLF systems for low peak current flashes does not allow an in-depth analysis of the majority of lightning flashes within TCs. This is because IC flashes comprise about $75 \%$ of all flashes in continental storms (Rakov 2016; Medici et al. 2017) and are, on average, characterized by lower peak currents than CGs (Rison et al. 1999; Koshak et al. 2004; Goodman et al. 2005). A notable portion of observational studies within TCs documented the existence of a relationship between the increase in CG flashes in the inner core of some TCs and their imminent intensification (Lyons et al. 1989; Molinari et al. 1994, 1999; Samsury and Orville 1994; Orville and Coyne 1999; Shao et al. 2005; Squires and Businger 2008; Thomas et al. 2010; Fierro et al. 2011; Bovalo et al. 2014; Stevenson et al. 2018). DeMaria et al. (2012) and Stevenson et al. (2016) suggested, however, that CG flash bursts in the inner core were, rather, associated with the end of an intensification phase, while a CG increase in the outer region of the TC was a better surrogate for the imminent intensification of these systems. Xu et al. (2017) supported DeMaria's findings using total lightning data from the spaceborne Lightning Imaging Sensor (LIS; Christian et al. 1999).

A comprehensive 10-yr survey of CG activity within North Atlantic TCs revealed that inner-core CG bursts inside (outside) the radius of maximum wind (RMW) were more conducive to intensification (weakening) (Stevenson et al. 2018). These observations are consistent with the modeling study of Hazelton et al. (2017), which confirmed the composite radar studies of Rogers et al. (2013), Wadler et al. (2018), and the seminal theoretical work of Schubert and Hack (1982) that convective heating inside the RMW is more efficiently retained by the inner core, leading to TC intensification. Following the earlier findings of Molinari et al. (1999), Stevenson et al. (2018) also documented that for a given inner-core CG burst, the future intensity of a TC is highly dependent on its prior intensity, with intensifying or steady-state TCs being more prone to intensify in the following $24 \mathrm{~h}$.

To provide a better picture of the relationships between convective patterns and intensity fluctuations of the TC, additional analyses utilizing total lightning data are desirable. This work is thus a logical follow-on to previous observational studies by providing an in-depth analysis of the evolution of total lightning within the major TC Maria (2017).

\section{Data description}

In this analysis, the following main datasets were used: 1) the total lightning data from the GLM, 2) the composite radar reflectivity fields from the French Lesser Antilles and Puerto Rico, and 3) a selected spectral band [i.e., infrared channel $14(11.2 \mu \mathrm{m})]$ from the advanced baseline imager (ABI). The analysis covers the period from 1200 UTC 18 September until 0000 UTC 21 September 2017, during which TC Maria reached its maximum intensity. 
Before beginning the descriptions of the datasets employed in this study, it is relevant to highlight that at the time of this writing, NOAA's GOES-16 satellite was not yet declared operational. Owing to the satellite's very recent launch on 19 November 2016, the data collected during the 2017 hurricane season are considered preliminary, as GOES-16 was still undergoing testing at the time (http://www.goes-r.gov). Moreover, given that the official best track data/storm reports for TC Maria (2017) have not yet been officially released, the current study made use of the National Hurricane Center (NHC) preliminary best track data. Owing to the small differences generally seen between the preliminary and best track datasets, especially when aircraft reconnaissance is actively flying, the overall impact on the current analysis is expected to be negligible.

\section{a. Lightning}

As mentioned in the introduction, the total lightning data utilized in this work were detected by the GLM instrument aboard the GOES-16 satellite. GLM camera pixels detect lightning flashes day and night with a horizontal resolution ranging between 8 and $12 \mathrm{~km}$, with an average detection efficiency nearing 90\% (Goodman et al. 2013). Although a topic of ongoing research, the detection efficiency of the GLM will likely vary depending on the time of day, geographical location (e.g., Fuchs et al. 2016), and optical cloud depth (Yoshida et al. 2009). The lightning detections from the GLM consist of a hierarchy of Earth-located lightning radiant energy measures, including events, groups, and flashes-all of which will be examined in this study. The lightning event is the primary element detected by the GLM, with the two other variables derived from the events by an algorithm adapted from the LIS instrument (Christian et al. 1999; Mach et al. 2007; Goodman et al. 2013). Lightning groups are a collection of one or more lightning events that satisfy temporal and spatial coincidence thresholds. Similarly, lightning flashes are a collection of one or more lightning groups that satisfy temporal and spatial coincidence thresholds [cf. Fig. 5 in Goodman et al. (2013) for an illustration]. To provide a simple illustrative context for the GLM lightning variables, Mach et al. (2007) suggested that a group could be thought of as a single lightning pulse (e.g., return stroke) and a flash as an amalgamation of several lightning pulses (e.g., negative CG flash producing multiple return strokes). A similar analogy with common meteorological terms for the GLM events is more difficult to establish since these essentially consist of transient optical (photon) emissions from a lightning flash that are instrument-dependent pixel measurements. Each pixel event is associated with a latitude-longitude coordinate of its centroid. For this analysis, the lightning data centroids initially stored in 20 -s intervals were binned in 1-h intervals and then projected onto a uniform 10-km Mercator grid, which was generated by the Weather Research and Forecasting Model postprocessing suite of tools (Skamarock and Klemp 2008). In the production/operational processing code for the GLM, a single-group flash filter, removing flashes associated with only one group, is applied to reduce false alarm rates (D. Mach 2018, personal communication). This is because most single-group flashes are typically viewed as noise. Knowing that some may be valid lightning flashes, however, no specific filtering was applied in this study for simplicity. Future and ongoing research with the GLM beyond the scope of this study should provide insight on the anticipated fraction of valid flashes within cohorts of single-group flashes in different classes of convective systems, including TCs.

It is relevant to note that, owing to recently addressed inaccuracies in the processing algorithm used during a large portion of 2017, the preliminary GLM dataset utilized in this study does suffer from location inaccuracies. To estimate the average error for this analysis, a distance offset histogram between GLM groups and the "best" match with either the Earth Networks Total Lightning Network (ENTLN; Liu and Heckman 2012) or GLD360 (Said et al. 2010; Holle et al. 2016) was computed for the entirety of the analysis period (from 1200 UTC 18 September to 0000 UTC 21 September 2017) within the spatial domain in Fig. 1 (K. Virts 2018, personal communication). The histogram data exhibited a peak at $\sim 17 \mathrm{~km}$, which would be equivalent to a mean location error of about two pixels over the Caribbean region, as this area lies near the center of the GLM field of view. We were informed that reprocessing of some of these data is planned, but no definite timeline could be provided at this time (K. Virts 2018, personal communication). While such a small displacement error would likely not affect the salient conclusions of this work, it may affect the portions of the current analysis focused on the location of the lightning, with respect to the RMW or inner-core quadrants, or on the exact spatial collocation between lightning and reflectivity maxima. Therefore, for the sake of completeness, potential discrepancies arising from this calibration error will be highlighted whenever appropriate in this analysis.

\section{b. Radar}

To establish temporal and spatial associations between lightning and precipitation/convection, the S-band radar 


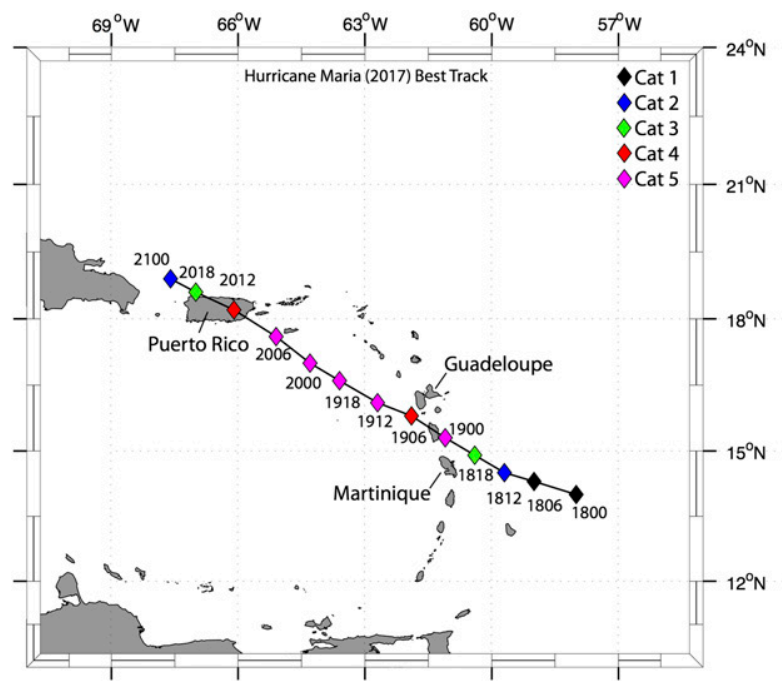

FIG. 1. Sketch of the preliminary 6-hourly track and intensity estimates from the NHC best track (http://www.nhc.noaa.gov/data/) during the period of analysis between 1200 UTC 18 Sep and 0000 UTC 21 Sep. Storm locations are highlighted by diamonds and color coded by intensity. To better highlight the main intensification period, two earlier times also are displayed.

data from Météo France of the French Antilles in La Martinique (Le Diamant, wavelength $\lambda=10.7 \mathrm{~cm}$ ) and La Guadeloupe (Le Moule, wavelength $\lambda=10.6 \mathrm{~cm}$ ) were perused. The reflectivity products provided by Météo France are static composite reflectivity fields derived from seven (six) scan elevation angles for Le Diamant (Le Moule), ranging between $0^{\circ}$ and $6^{\circ}$ $\left(4.2^{\circ}\right)$ (S. Denizanne 2017, personal communication). The original data are provided in 5-min intervals in GeoTIFF format on an azimuthally equidistant grid, with origin set at the respective radar locations. To establish comparisons with the lightning fields, the composite reflectivity fields were reprojected onto a Mercator grid. Hurricane Maria was in good range from these two radars between about 1200 UTC 18 September and 1200 UTC 19 September. After that, the U.S. Weather Surveillance Radar-1988 Doppler (WSR-88D) in Cayey, Puerto Rico (TJUA), was utilized for the period beginning at 1800 UTC 19 September until the destruction of the radar at about 2000 UTC 20 September. While Maria was sampled multiple times by the Air Force Hurricane Hunter aircraft starting on 17 September 2017, no NOAA WP-3D aircraft reconnaissance missions were flown into Maria prior to 22 September 2017 (P. Reasor 2017, personal communication). The lack of radar data on 21 September 2017 in the case of this major hurricane illustrates how the high spatiotemporal data from GOES-16 helped fill a critical void. Radar data from Barbados were, unfortunately, not made available for this study.
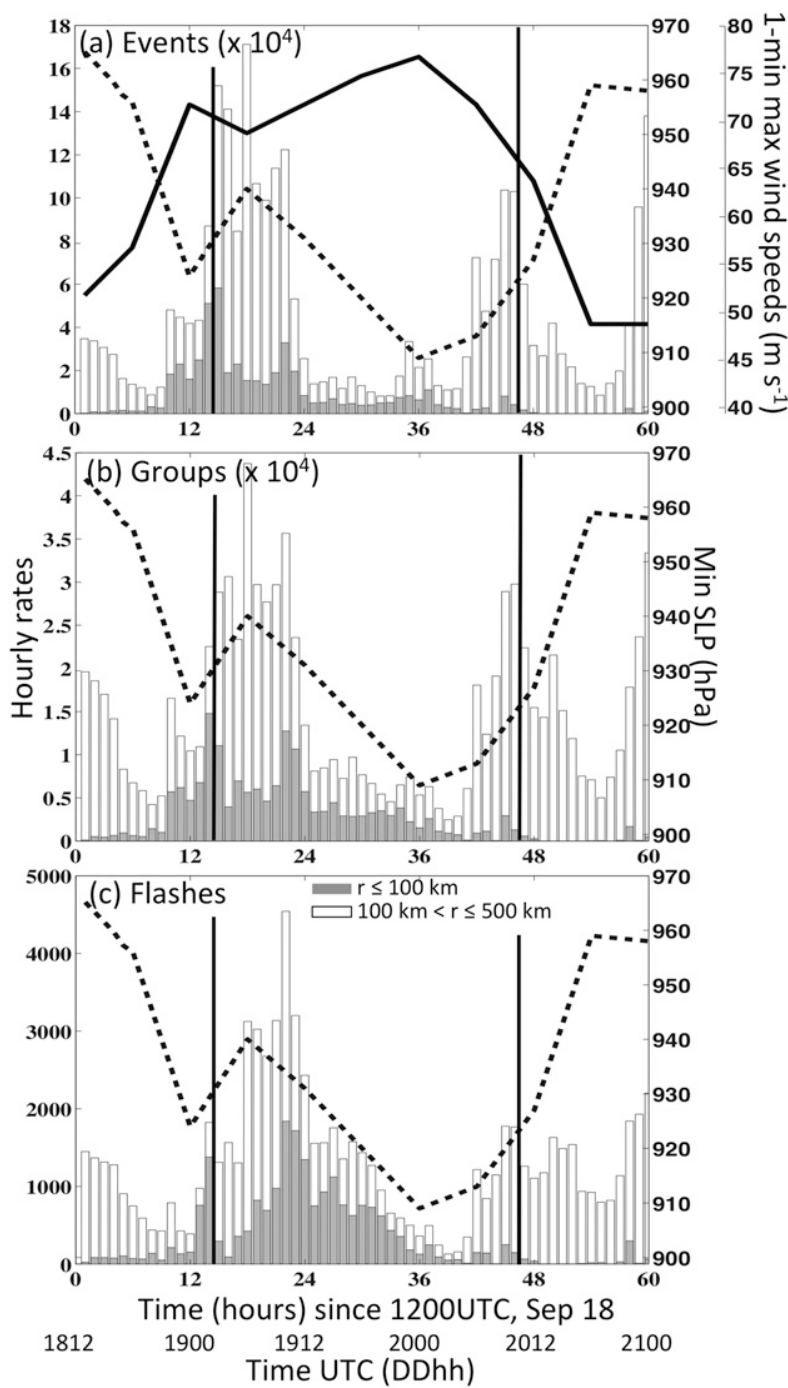

FIG. 2. Stack bar charts of the hourly rates for the GLM (a) events, (b) groups, and (c) flashes. The hourly rates were accumulated within a storm-following disk mask with radius $r$ of $500 \mathrm{~km}$, with the origin based on the estimated storm center from the NHC (preliminary) best track data (http://www.nhc.noaa.gov/data/). The total hourly rates were subdivided by the outer region (white bars) and the inner core (gray bars). Inner-core rates include data within an $r=100-\mathrm{km}$ disk, while the outer region sums all data within the area defined by $100<r \leq 500 \mathrm{~km}$. The sum of the white and gray bar flash rates is the "storm total" rate, which is shown on the left axis. Overlaid with the lightning hourly rates is the hourly pressure trace based on the estimates from the NHC best track data (dashed black line; hPa). For reference, time series of the maximum 1-min sustained surface wind speeds (thick black line) are shown in (a). The $x$ axis shows the time in hours after 1200 UTC $18 \mathrm{Sep}$, and for convenience, the time in day/hour (UTC) format. Vertical black lines show the times of landfall in Barbuda and Puerto Rico. With this setup, the first hour with accumulated GLM data is at 1300 UTC 18 Sep. 


\section{c. $A B I$}

The ABI is the primary instrument aboard GOES-16 in terms of payload and features 16 spectral bands (compared to five on GOES-13), which include two visible channels, four near-infrared channels, and 10 infrared (IR) channels. The ABI on GOES-16 provides 3 times more spectral information, 4 times the spatial resolution, and 5 times faster coverage than GOES-13 (http://www.goes-r.gov).

The displacement errors vary with satellite viewing angle (cloud latitude and longitude, satellite location). For latitudes near $40^{\circ} \mathrm{N}$, displacements are around $10 \mathrm{~km}$ for a cloud height of $10 \mathrm{~km}$. In the case of GLM data overlaid on uncorrected GOES-16 ABI imagery, there is little error between the cloud and lightning relative locations if the parallax correction is removed from the GLM data (as done herein; see online supplemental material). If the cloud locations are corrected for parallax, and GLM data include the default parallax correction, then relatively small errors are expected.

In this study, emphasis will be placed on the ABI IR channel $14(11.2 \mu \mathrm{m})$ radiance fields in mesoscale scan mode. In this mode, the ABI provides coverage over a $1000 \times 1000 \mathrm{~km}^{2}$ domain every $30-60 \mathrm{~s}$ at a spatial resolution of $2 \mathrm{~km}$. This provides an unprecedented opportunity for forecasters and researchers to analyze the evolution of deep convective regions (and their association with total lightning) within TCs. To establish direct comparisons with both the radar and the GLM data, the ABI data were interpolated from their native geostationary projection onto a Mercator grid.

\section{Results}

\section{a. General lightning evolution}

During the analysis period, Hurricane Maria experienced two main deepening phases. The first, most prominent one started about $6 \mathrm{~h}$ prior to the beginning of the analysis period-namely, at about 0600 UTC 18 September-and ended at 0000 UTC 19 September (Figs. 1, 2a). During this 18-h period, Maria deepened from a category 1 to a category 5 hurricane on the SaffirSimpson scale just prior to making landfall on the island of Barbuda at about 0200 UTC 19 September (Figs. 1, 2a). In the first $9 \mathrm{~h}$ of the analysis period during this first intensification cycle, total lightning was largely confined in the outer region (Fig. 2a). During this time, the GLM events, groups, and flashes all underwent a slight decreasing trend (Figs. 2a-c). After about 2200 UTC 18 September, the inner-core hourly rates of GLM events and groups experienced a notable increase by about a factor of 4 to 5 (Figs. 2a,b). A similar increase for the inner-core flashes occurred only $3 \mathrm{~h}$ later, namely, at 0100 UTC 19 September. This period coincided with the time just prior to landfall in Barbuda, during which Maria experienced a brief period of weakening from a category 5 to a category 4 TC between about 0000 and 0600 UTC 19 September. During this 6-h interval, the total lightning rates in the inner core exhibited a sharp increase for about a 2-h period. Additionally, lightning in the outer region also increased, especially after the eye of Maria passed the island of Barbuda at about 0400 UTC 19 September (Figs. 1,2). Though land may have played a role in the short 6-h observed weakening and the sharp increase in lightning, the above results agree with DeMaria et al. (2012) and Stevenson et al. (2016), in which an inner-core lightning burst is indicative of the end of an intensification cycle, while lightning in the outer regions peaks earlier in the intensification phase.

During the second intensification phase, between 0600 UTC 19 September and 0000 UTC 20 September, Maria regained strength into a category 5 storm and reached its maximum intensity at about 0000 UTC 20 September [minimum surface pressure $(\mathrm{minSLP}) \approx 910 \mathrm{hPa}$; Fig. 2]. The first $6 \mathrm{~h}$ of this deepening phase were characterized by notable inner-core and, especially, outer-region lightning activity. After 1200 UTC 19 September-when Maria regained category 5 status - total lightning rates in both the inner core and outer region experienced a noticeable drop, with the largest seen in the outer region. From 1200 UTC 19 September until Maria reached its maximum intensity $12 \mathrm{~h}$ later, relatively less lightning was produced in the outer region for the events (Fig. 2a). During this 12-h period, Maria showed a nearly steady inner-core lightning activity in terms of hourly rates of events and groups. The GLM flash rates, however, exhibit a distinct peak during this period (cf. Fig. 2c and Figs. 2a,b). This indicates that, for a given hourly lightning event (group) rate, Maria's inner core produced more flashes at and a few hours after 1200 UTC than later on at 1900-2200 UTC 19 September (Figs. 2a-c). In other words, the average number of events (groups) associated with a single flash near 1200 UTC was larger than at 1900-2200 UTC 19 September. It is relevant to note that this result might be affected if a single-group flash filter was applied to the GLM data. Consistent with DeMaria et al. (2012), the beginning of this second intensification cycle is characterized by a marked increase in outer-band lightning flash rates (with similar trends seen for groups and events). Inner-core flash rates also exhibit a relative increase during the early stage of that intensification period, which is less marked for the GLM groups and, especially, for the events. This second deepening cycle 


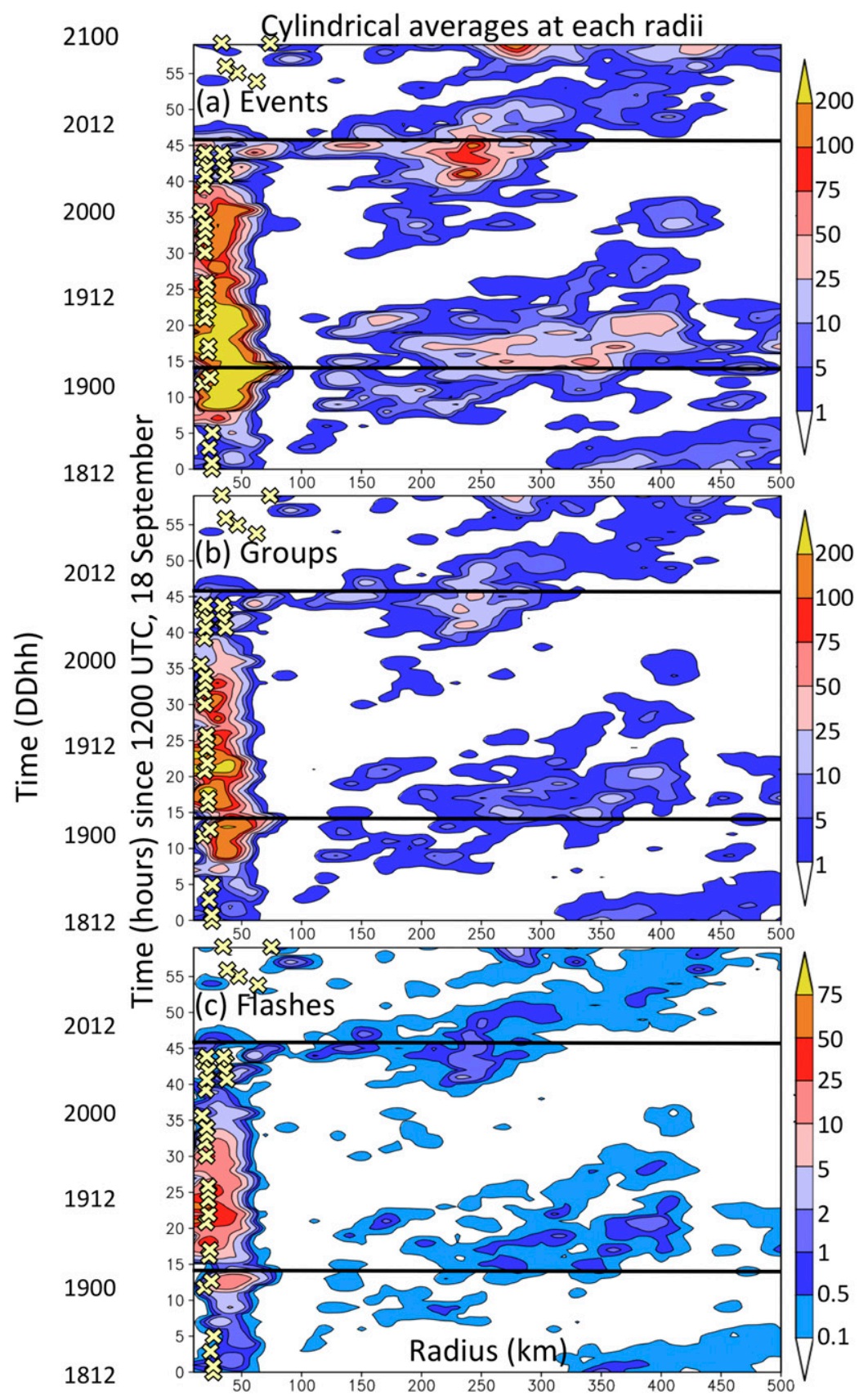

FIG. 3. Storm-centered Hovmöller diagrams of the azimuthally averaged hourly GLM (a) events, (b) groups, and (c) flashes. GLM data were interpolated onto a stormfollowing cylindrical grid with a resolution of $10 \mathrm{~km}$ in the radial and $2^{\circ}$ in the azimuthal directions. As in Fig. 2, time is shown in hours after 1200 UTC 18 Sep, and for convenience, in day/hour (UTC) format with two horizontal black lines denoting the approximate time of landfall in Barbuda (hour 14) and Puerto Rico (hour 46). The yellow crosses with black outlines denote the flight-level $(700 \mathrm{hPa}) \mathrm{RMW}$ estimated from USAF reconnaissance flight, HDOB, 30-s data. As will be documented later, TC Maria underwent an eyewall replacement cycle later in the analysis period. Thus, some of the times on the $y$ axis, namely, hours 41-44 and 60, show the estimated RMW associated with the wind maxima in the inner and outer eyewall, respectively. 
occurred within a 24 -h period of the inner-core burst documented above, which was preceded by the main deepening phase of Maria (i.e., prior to 0000 UTC 19 September; Fig. 2). This observation is in line with the comprehensive survey study of Stevenson et al. (2018), in which intensifying TCs experiencing an inner-core burst were more likely to intensify within the next $24 \mathrm{~h}$.

After reaching its maximum intensity, Maria gradually weakened to a category 4 storm prior to making landfall in Puerto Rico (Figs. 1, 2a), coincident with an eyewall replacement cycle (discussed later). After interacting with the mountainous terrain of Puerto Rico, Maria quickly weakened further to category 2 status. During this period, Maria's lightning was almost exclusively confined in its outer region, with very similar trends seen for the events, groups, and flashes (Fig. 2).

To provide a more comprehensive view of the total lightning evolution in this hurricane, the GLM data were interpolated onto a storm-following cylindrical grid to visualize the GLM events, groups, and flashes in Hovmöller space (time-radius; Figs. 3, 4). The resolution in the radial direction was $10 \mathrm{~km}$ and $2^{\circ}$ in azimuth. These Hovmöller diagrams also display RMW estimates based on flight-level $(700 \mathrm{hPa}), 30$-s high-density observations (HDOB) from the U.S. Air Force (USAF) reconnaissance missions. The period of analysis includes RMW data estimates from 27 flight legs from seven separate reconnaissance flights (https://www.nhc.noaa. gov/archive/recon/2017/AHONT1/). The RMW from each individual flight leg was computed using a complete pass through the eyewall, eye, and back through the eyewall. To ensure that both the RMW and lightning remain in the same reference coordinate system with respect to the TC center, the latitude-longitude locations of the maximum wind from the HDOB observations were compared to the respective times of the hourly interpolated best track data used in Fig. 2. The flight-level RMW was preferred over the surfaceestimated RMW because it is closer to the layer where the bulk of the noninductive charging, and hence lightning discharges, occurs in the eyewall of a TC (between $0^{\circ}$ and $-20^{\circ} \mathrm{C}$; Brooks et al. 1997; Saunders and Peck 1998; Black and Hallett 1999; Saunders et al. 2001; Fierro et al. 2007, 2013, 2015; Fierro and Mansell 2017, 2018). Moreover, the flight-level RMW is measured, whereas the RMW at the surface that is estimated by the Stepped-Frequency Microwave Radiometer (SFMR) suffers from attenuation in regions of high rain rates (Uhlhorn and Black 2003).

The Hovmöller diagrams illustrate that the lightning was tightly packed near the inner core within a radius $r$ of about $50 \mathrm{~km}$ (Figs. 3, 4). These also reveal the presence of a systematic minimum in total lightning between about $r=75$ and $125 \mathrm{~km}$, which is associated with the inner-band stratiform region of the TC (Cecil et al. 2002; Cecil and Zipser 2002). The inner core of Maria produced the largest values of lightning event, group, and flash densities (Fig. 4). The respective azimuthal maxima of hourly density rates of events, groups, and flashes coincide generally well in space and time, although some quantitative differences should be noted. For instance, the inner-core flash density maximum at about $13 \mathrm{~h}$ is smaller than the maximum occurring at about $22 \mathrm{~h}$, while for the events, the converse is observed (Figs. 4a,c). For the groups, however, these two maxima remain comparable (Fig. 4b).

During about 0000 and 1200 UTC 19 September, some of the GLM lightning contours appear to be more systematically clustered near the flight-level $(700 \mathrm{hPa})$ RMW (Figs. 3, 4), with the highest flash rates $(>50$ flashes per hour) occurring within the flight-level RMW. Coincidentally, TC Maria underwent a brief deepening period (from 0600 UTC 19 September until 0000 UTC 20 September; Fig. 2), which would be consistent with the recent findings of Stevenson et al. (2018) for Atlantic TCs. Recalling that the preliminary GLM data used in this analysis suffer from a $\sim 17-\mathrm{km}$ location error (K. Virts 2018, personal communication), and given the relatively short period of analysis, it is important to reiterate that caution should be advised in interpreting results of this particular analysis relying on positioning precision of the lightning on the order of $10-20 \mathrm{~km}$. It is also important to note that given the outward tilt of the eyewall updraft and the fact that an optical instrument, such as the GLM, detects upperlevel ( $\geq 10 \mathrm{~km}$ ) flashes (mainly ICs) more readily than lower-level $(\leq 7 \mathrm{~km})$ flashes (Yoshida et al. 2009), the lightning contours located outside the $700-\mathrm{hPa}$ RMW in Figs. 3 and 4 may represent latent heating inside the 700-hPa RMW.

To complement the Hovmöller diagrams in Figs. 3 and 4 and the time series in Fig. 2, the lightning data were subdivided into four quadrants relative to intercardinal directions and to the 850-200-hPa shear vector (Fig. 5). While it is common usage to refer to the TC quadrants relative to storm motion, this would not change the salient conclusions of this analysis, which are later supported by the results presented in the subsequent section. Figure 1 shows that during the analysis period, Maria had an almost constant storm motion vector almost due west-northwest. Thus, the main impact of including a $\sim 22.5^{\circ}$ tilt in the intercardinal quadrants' configurations in Fig. 5 would be to increase (decrease) the amount of lightning in the northeast (southeast) quadrant, with little change seen in the northwest quadrant. The 6-hourly deep-layer shear (850-200 hPa) 


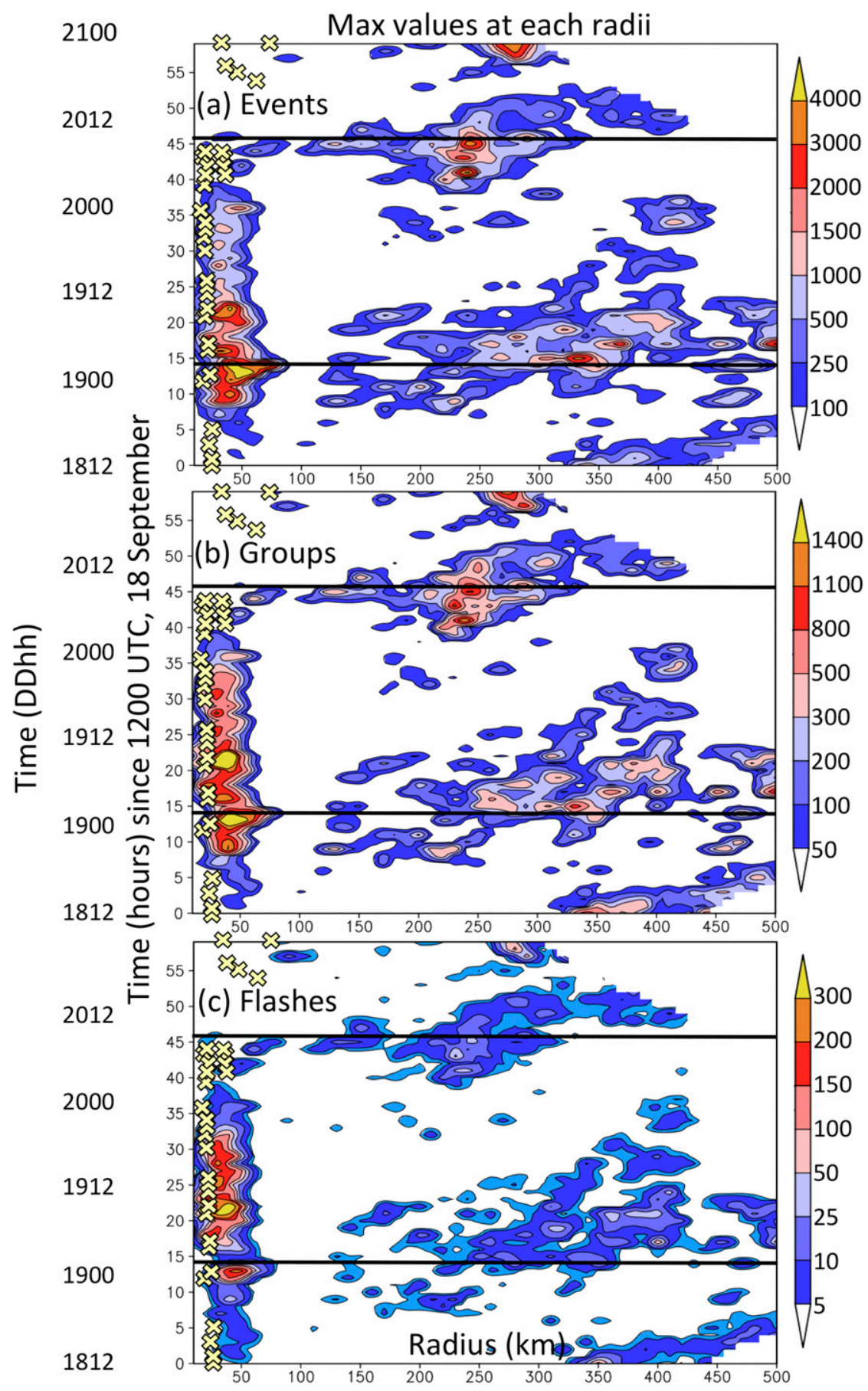

FIG. 4. As in Fig. 3, but for the maximum values at each radius.

data were extracted from the Statistical Hurricane Intensity Prediction Scheme (SHIPS; DeMaria and Kaplan 1994, 1999; DeMaria et al. 2005; Kaplan et al. 2010) database. To determine the shear relative quadrants at each hour within a given 6-h bin, the average shear calculated from the beginning and end time values was perused.
During the period of maximum intensity, Maria produced the vast majority of its inner-core and outer-region lightning in the southeast quadrant, with percentiles ranging between $77 \%$ and $\sim 90 \%$ (Figs. $5 \mathrm{a}$,b). Incidentally, the least electrically active region of this TC for both the inner core and the outer region was the northwest quadrant, with the northeast and southwest 
(a) Total counts Relative to cardinal directions (b) Percentiles

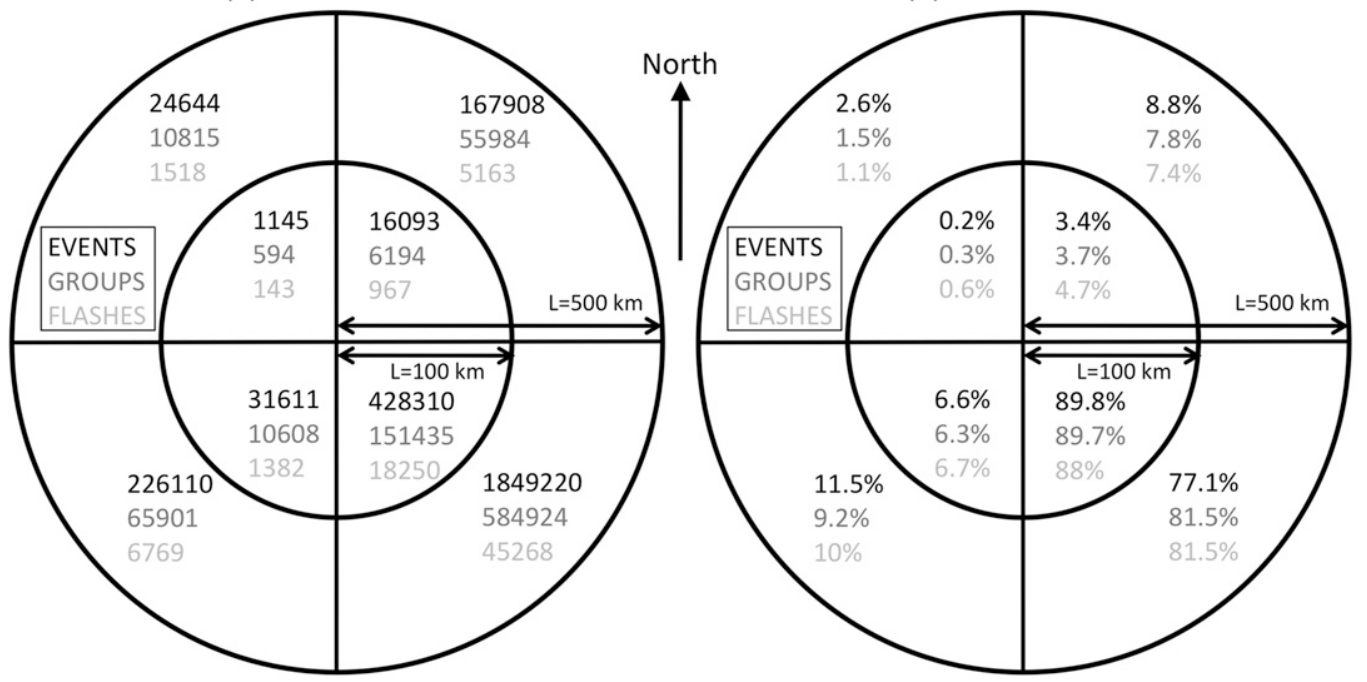

(c) Total counts

Shear-relative

(d) Percentiles

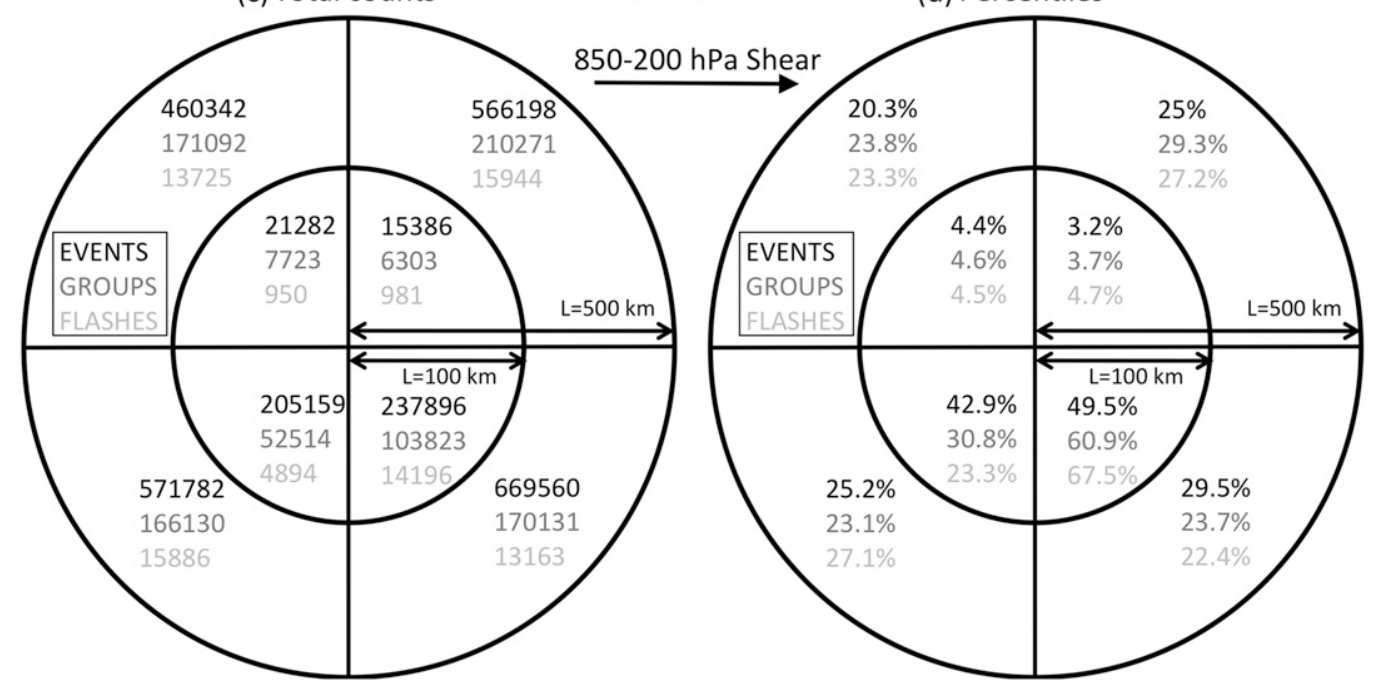

FIG. 5. Diagram showing the (a) total count and (b) percentiles of the events, groups, and flashes in black, dark gray, and light gray, respectively, relative to the cardinal directions over the entire analysis period (1200 UTC 18 Sep-0000 UTC 21 Sep) within the inner core and outer region, divided by quadrants within the cylinders described in Fig. 2, which are on the Mercator grid. (c),(d) As in (a),(b), but for the 850-200-hPa shear relative totals. The 6-hourly shear data were extracted from the SHIPS database. For hourly data within a given 6-h bin, the average shear direction from the beginning and end values of the 6-h bin was used to compute the shear-relative quadrants.

quadrants producing overall similar respective lightning fractions. Given the weak ambient wind shear in the vicinity of TC Maria at the time $\left(<4 \mathrm{~m} \mathrm{~s}^{-1}\right.$; see later in the analysis), these results for the inner core appear to contrast with the idealized modeling study of Fierro and Mansell (2017), wherein a major TC evolving in an initial environment at rest (no ambient wind shear) with favorable sea surface temperatures (SSTs) $\left(\sim 28^{\circ} \mathrm{C}\right.$; Williams and Renno 1993) and a very slow $\left(<5 \mathrm{~m} \mathrm{~s}^{-1}\right)$ westward mean storm motion produced the vast majority of its inner-core lightning in the northwest quadrant (equivalent to the front-right quadrant in their case). This was hypothesized to arise from storm-motion-induced enhancement of boundary layer convergence in the front-right quadrant (Shapiro 1983; Shapiro and Franklin 1999). Because of displacement errors mentioned earlier with the GLM, it is thus possible that the azimuthal placement of the lightning relative to the quadrants in the inner core may not be correct. At this time, Maria was moving west-northwest at $\sim 4 \mathrm{~m} \mathrm{~s}^{-1}$ and exhibited a rather compact RMW (Fig. 5), which would likely amplify any southeast displacement of the GLM lightning. Reinforcing 
this, a later analysis using the WWLLN data with track data interpolated to the minute and the ABI/GLM overlay animation in the supplemental material both suggest that, instead, the inner-core CG lightning was more confined to the northwest quadrant. One potential viable explanation for this atypical lightning pattern, however, could be tied to the respective detection of IC flashes at upper levels versus CGs farther down. In TC Rita (2005), which exhibited a similar eyewall diameter and TC intensity to Maria during the analysis periods considered, Fierro et al. (2011) found that in contrast to CGs, IC flashes could be used to track the revolution of individual convective events around the eyewall. Most IC flash clusters completed a full revolution in about $15-25 \mathrm{~min}$. Given that CG flashes seen by WWLLN are more consistently located in the northwest (front right) quadrant (see section 3c), it is thus possible that the flash density maximum in the southern eyewall of TC Maria may be associated with the rotation of IC flashes from electrified convection initially developing in the front-right quadrant of the TC. The apparent maximum in lightning density there would be consistent with 1) the GLM optical instrument being able to detect upper-level ICs more readily than CG flashes at lower levels (Yoshida et al. 2009), 2) IC flashes generally outnumbering CGs by a factor ranging from 2 to 3 in nonsevere storms (e.g., Boccippio et al. 2001; Schultz et al. 2011), and 3) the WWLLN analysis (see section 3c) showing a noticeably larger IC to CG ratio in the inner core of Maria.

The shear heading changed from about $300^{\circ}-330^{\circ}$ between 0000 UTC 19 September and 0000 UTC 20 September to values ranging within $50^{\circ}-130^{\circ}$ after 0000 UTC 20 September. When the deep-layer shear was accounted for in the calculation of the lightning totals within each quadrant (Figs. 5c,d), some notable differences ought to be highlighted. First, the inner-core lightning becomes more evenly distributed between the lower-left (upshear right) and lower-right (downshear right) quadrants, and second, the lightning totals in the outer band become more evenly distributed among all four quadrants. Given that Maria reached category 5 status with a nearly perfectly axisymmetric inner core (see later in this section), it is not surprising to find that during the analysis period, the 850-200-hPa shear magnitudes in the SHIPS data were overall small (i.e., $<4.5 \mathrm{~m} \mathrm{~s}^{-1}$ ). These results contrast with Corbosiero and Molinari (2002), who found that in weak shear $\left(<5 \mathrm{~m} \mathrm{~s}^{-1}\right)$, inner-core (CG) lightning still occurs downshear a majority of the time $(69 \%)$.

Of interest to operational forecasters is the existence of potential relationships among lightning rates in specific regions of the TC and intensity trends (particularly future intensity changes). For instance, SHIPS (DeMaria and Kaplan 1994, 1999; DeMaria et al. 2005;
Kaplan et al. 2010) makes use of environmental parameters (predictors) for the rapid intensification index (RII; DeMaria et al. 2012). Some experimental versions of the RII include the axisymmetric component of CG flash rates within the inner core and outer region of the TC derived from ground-based, very low-frequency sensors (e.g., World Wide Lightning Location Network; Abarca et al. 2011; DeMaria et al. 2012). It is thus relevant to determine if total lightning data from the GLM could be used as a potential predictor in SHIPS or other similar statistical schemes. Since lightning in TCs is generally very episodic, it is also of interest to researchers focusing on storm-scale electrification processes to gain a better understanding of the relationship(s) between an estimate of "current" lightning activity (i.e., hourly rates) and the present estimate of storm intensity. Thus, two separate correlation statistics were computed among each of the three lightning metrics (events, groups, and flashes) provided by the GLM for the inner core, outer region, and storm total lightning counts. The first considered the hourly accumulated lightning and the current estimate of storm intensity, namely, the minSLP and the maximum 1-min surface wind speed (maxWSP). The second employed the 6-hourly lightning rates and the future 6-h change in storm intensity. For the correlation statistics using hourly data, the 6-hourly best track data (minSLP and maxWSP) were linearly interpolated to hourly time series to match the hourly binning of the lightning. Because of the relatively small sample size of the time series in either the hourly dataset (i.e., 60 elements; Fig. 2) or the 6-hourly dataset (i.e., 10 elements) and the desire to establish the statistical significance of the correlations obtained, the data were subjected to a bootstrapping technique (i.e., no a priori distribution assumed) involving 1000 random samples. Additional tests (not shown) were conducted using 5000 samples and revealed, overall, quantitatively similar results. To better visualize and interpret the results from the bootstrapped correlation statistics, box-and-whisker diagrams highlighting the significance at the $5 \%$ variance level were computed (Fig. 6). A given correlation is deemed insignificant whenever the $5 \%$ variance level crosses the zero correlation line. For clarity, references to correlations in this section imply median correlation values $R$.

Overall, the most robust relationship between lightning and TC intensity was obtained between maxWSP and the inner-core groups and flash density rates with $R$ values near 0.5 (Fig. 6a). The inner-core events exhibited a slightly lower, but nonetheless statistically significant, correlation with maxWSP of about 0.4 . The outer-region lightning, on the other hand, was generally 
(a) maxWSP

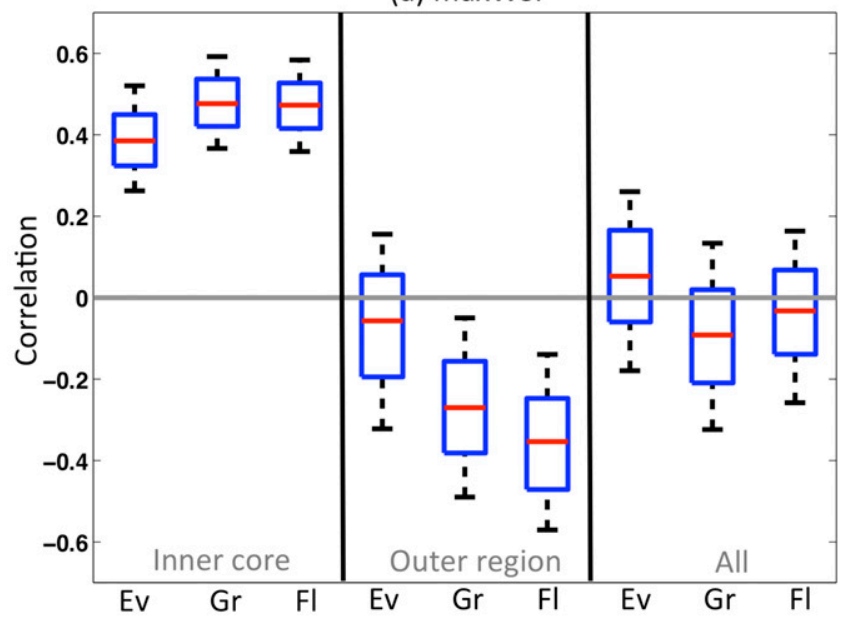

(c) Future 6-h change in maxWSP

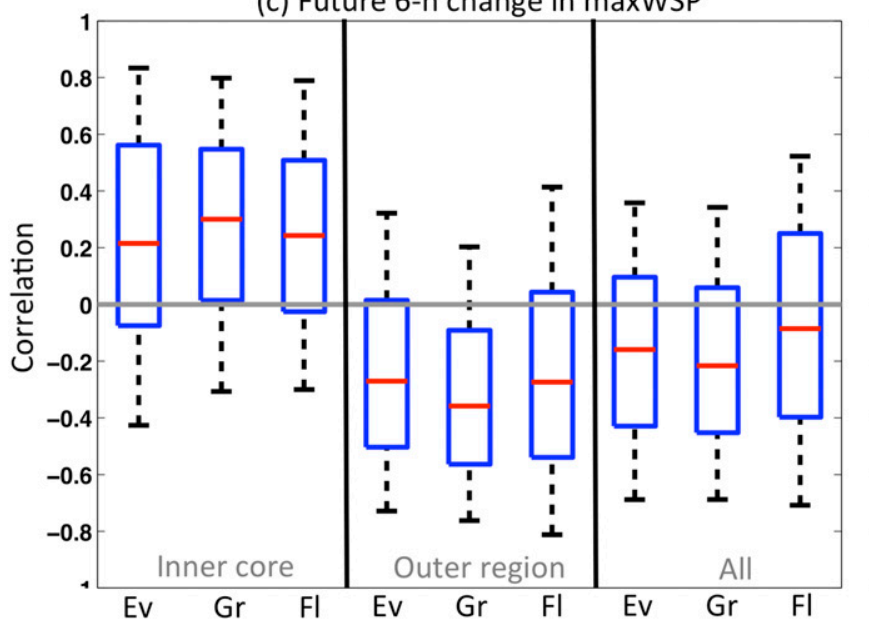

(b) $\operatorname{minSLP}$

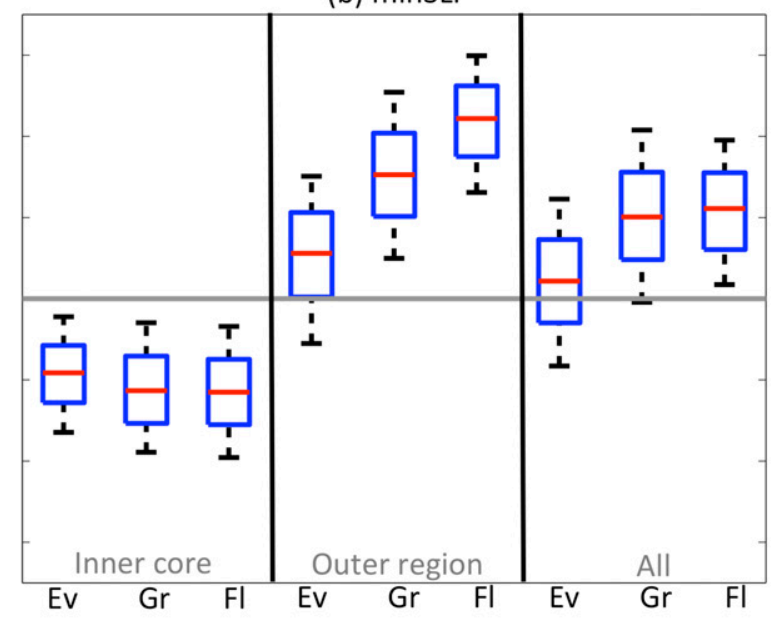

(d) Future 6-h change in minSLP

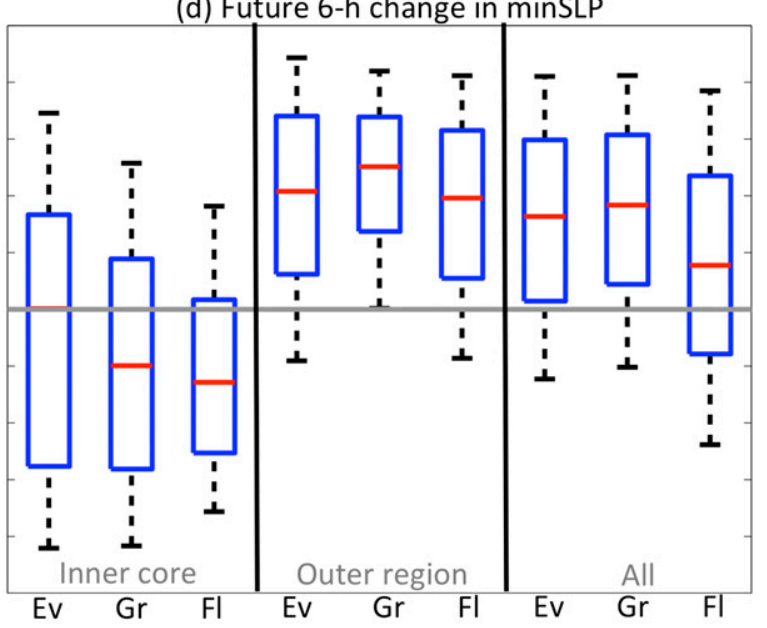

FIG. 6. Box-and-whisker plots of 1000-sample bootstrapped Pearson's correlation between the hourly time series of events (Ev), groups (Gr), and flashes (Fl) for (a) maxWSP and (b) minSLP. (c),(d) As in (a),(b), but for future 6-h change in maxWSP and minSLP, respectively. The red line depicts the median correlation. The blue box shows the lower and upper quartiles $(25 \%$ and $75 \%)$. The 2.5 th- and 97.5th-percentile correlation values are shown at the end bars of the dotted lines outside the blue box. The correlation statistics for $\mathrm{Ev}, \mathrm{Gr}$, and $\mathrm{Fl}$ were computed for the inner core, outer region, and storm total, respectively. For convenience, the statistics for the inner core, outer region, and storm total are separated by a vertical black line.

negatively correlated with maxWSP, with only the groups and flashes showing statistically significant $R$ of $\sim-0.3$ and $\sim-0.35$, respectively (Fig. 6a). Storm total lightning rates showed, overall, no statistically significant relationship with maxWSP (Fig. 6a). Because minSLP and maxWSP in a TC generally are mutually highly negatively correlated (when minSLP increases, maxWSP decreases, and vice versa; Fig. 2), the correlation statistics obtained between minSLP and lightning reverse sign (Figs. 6a,b). Although arguably marginal, all three measures of lightning rates in the inner core show statistically significant correlations with minSLP, with $R$ ranging from about -0.2 for the events to $\sim-0.25$ for the groups and flashes. The magnitudes of the aforementioned $R$ values for minSLP in the inner core are smaller (by $\sim 0.1$ ) than the respective $R$ values for maxWSP (Figs. 6a,b). The $R$ magnitudes between lightning in the outer region and minSLP are, overall, quite similar to those for maxWSP. When storm total lightning rates are considered, only the flashes exhibit a statistically significant relationship with minSLP, which is marginal $(R \sim 0.2$; Fig. $6 \mathrm{~b})$. We note that because the majority of the storm total flashes occurred in the outer region during this analysis period (Figs. 2, 5), the correlations for the whole storm are largely reflected by those in the outer region (Fig. 6). The overall pattern with intensity suggests that more total lightning occurs with a stronger TC (i.e., higher maxWSP or lower minSLP), 
which contradicts the CG-based study of Abarca et al. (2011) that found higher lightning rates in weaker TCs. The current study only examines one case for $60 \mathrm{~h}$, so more research is necessary to confirm if this relationship holds for a larger sample.

When considering the future 6-hourly changes in either minSLP or maxWSP, most correlations become insignificant owing to the very small sample size used (Figs. 6c,d). Bearing this in mind, it is interesting to note, however, that the best correlations obtained are between the future 6-hourly changes in minSLP and the 6-hourly lightning rates in the outer region (Fig. 6d). Despite the short duration of the analysis for operational standards and the fact that only one single case is considered, this may suggest consistency with the more general results of DeMaria et al. (2012), in which lightning in the outer region serves as a better surrogate for future intensity changes in contrast to the inner core, which indicates the end of an intensification phase.

\section{b. Relationships among lightning, radar, local environment, and cloud fields}

Before beginning the description of the results, it is relevant to note that this analysis considered GLM events, groups, and flashes. Because the above results showed that, overall, their respective trends are similar, this section will only focus on the horizontal crosssections of GLM flashes.

To complement the overall view of Maria's total lightning evolution presented in the previous section, this analysis examines how the spatial distribution of lightning densities relates to 1 ) the precipitation fields, as measured by composite radar reflectivity, 2) cloud depth/morphology, as measured by the ABI outgoing radiance fields (in the IR range for day/night coverage), and 3) the local environment in the vicinity of the TC in terms of the SST fields, the ocean heat content (OHC), and the $850-200-\mathrm{hPa}$ shear (heading and magnitude). The SST data are the daily Reynolds SST on a $0.25^{\circ}$ grid, based on a combination of satellite observations and in situ platforms (Reynolds et al. 2007; Reynolds and Smith 1994). The OHC fields, also on a $0.25^{\circ}$ grid, were extracted from the Navy Coupled Ocean Data Assimilation database described in Knaff et al. (2013). The data assimilation used the approach from Cummings (2005). The $\mathrm{OHC}$ values are computed from the surface to the depth of the $26^{\circ} \mathrm{C}$ isotherm.

At the beginning of the analysis period at $1200-1300$ UTC 18 September, Maria did not yet show evidence of any discernable eye in the ABI imagery (Fig. 7a). The reflectivity fields from the Météo France radar site in $\mathrm{La}$ Martinique, however, indicate that at this time, Maria was starting to exhibit a well-defined eye in its precipitation field (Figs. 7b,c), which was associated with weak lightning activity (Fig. 7a). This is consistent with the U.S. Air Force reconnaissance vortex data message at that time (1300 UTC 18 September), indicating a circular eye with a diameter of $\sim 22 \mathrm{~km}$ and that was open in the southwest. Despite an inner core being characterized by comparably low values of outgoing radiance, the outer bands within the eastern semicircle produced the bulk of the lightning at this time (Fig. 7a), which were outside the $\sim 400-\mathrm{km}$ range from the Météo France radars (dashed white rectangle in Fig. 7a). The western semicircle also contains narrow precipitation bands, characterized by $40+\mathrm{dB} Z$, but these were devoid of lightning (Fig. 7). At this time, SST and OHC fields ahead of the TC, combined with relatively weak deep-layer shear $\left(<3 \mathrm{~m} \mathrm{~s}^{-1}\right)$, indicate relatively more favorable conditions for intensification, with SST values ranging between $29^{\circ}$ and $30^{\circ} \mathrm{C}$ and $\mathrm{OHC}$ nearing $70 \mathrm{~kJ} \mathrm{~cm}^{-2}$ (Figs. $7 \mathrm{~d}, \mathrm{e}$ ). These SST (shear magnitude) values are noticeably higher (lower) than the climatology for the month of September, based on the entire SHIPS database in the Atlantic (starting in 1982), which is $27.6^{\circ} \mathrm{C}\left(\sim 8.1 \mathrm{~m} \mathrm{~s}^{-1}\right)$. This still holds when only considering the September climatology of the SSTs and deep-layer shear magnitudes within the analysis domain (Fig. 1), which are $28.8^{\circ} \mathrm{C}$ and $\sim 7.3 \mathrm{~m} \mathrm{~s}^{-1}$, respectively. Thus, based on the evidence provided by the climatological averages derived from the SHIPS database, the environment in which TC Maria intensified into a category 5 storm was unusually favorable. Incidentally, the lightning in the outer region to the east and southeast (Fig. 7a) is collocated with regions of relatively higher OHC and SSTs (Figs. 7d,e).

A few hours prior to making landfall in Barbuda (0000 UTC 19 September), Maria exhibited a well-defined solid ring of composite reflectivities exceeding $35 \mathrm{dBZ}$ on radar (Figs. 8b,c), which was associated with a clear eye in the ABI IR imagery, surrounded by low outgoing radiance values (Fig. 8a). At this time, which coincided with the end of the first intensification phase (Figs. 1,2), the inner core/eyewall of Maria produced relatively larger flash density rates ( $>25$ flashes $\mathrm{km}^{-2} \mathrm{~h}^{-1}$, Fig. 8a) an observation consistent with DeMaria et al. (2012). Figure 6 a shows that during this $1-\mathrm{h}$ period, the southern portion of the eyewall produced the overwhelming majority of the lightning. The outer region in the southern semicircle was characterized by lightning-active cells with comparatively lower flash densities ranging between 1 and $\sim 15 \mathrm{~km}^{-2} \mathrm{~h}^{-1}$, which are well captured by the Météo France radar in La Martinique (Figs. 8b,c). Elsewhere around the TC (i.e., $r \leq 500 \mathrm{~km}$ ), lightning 

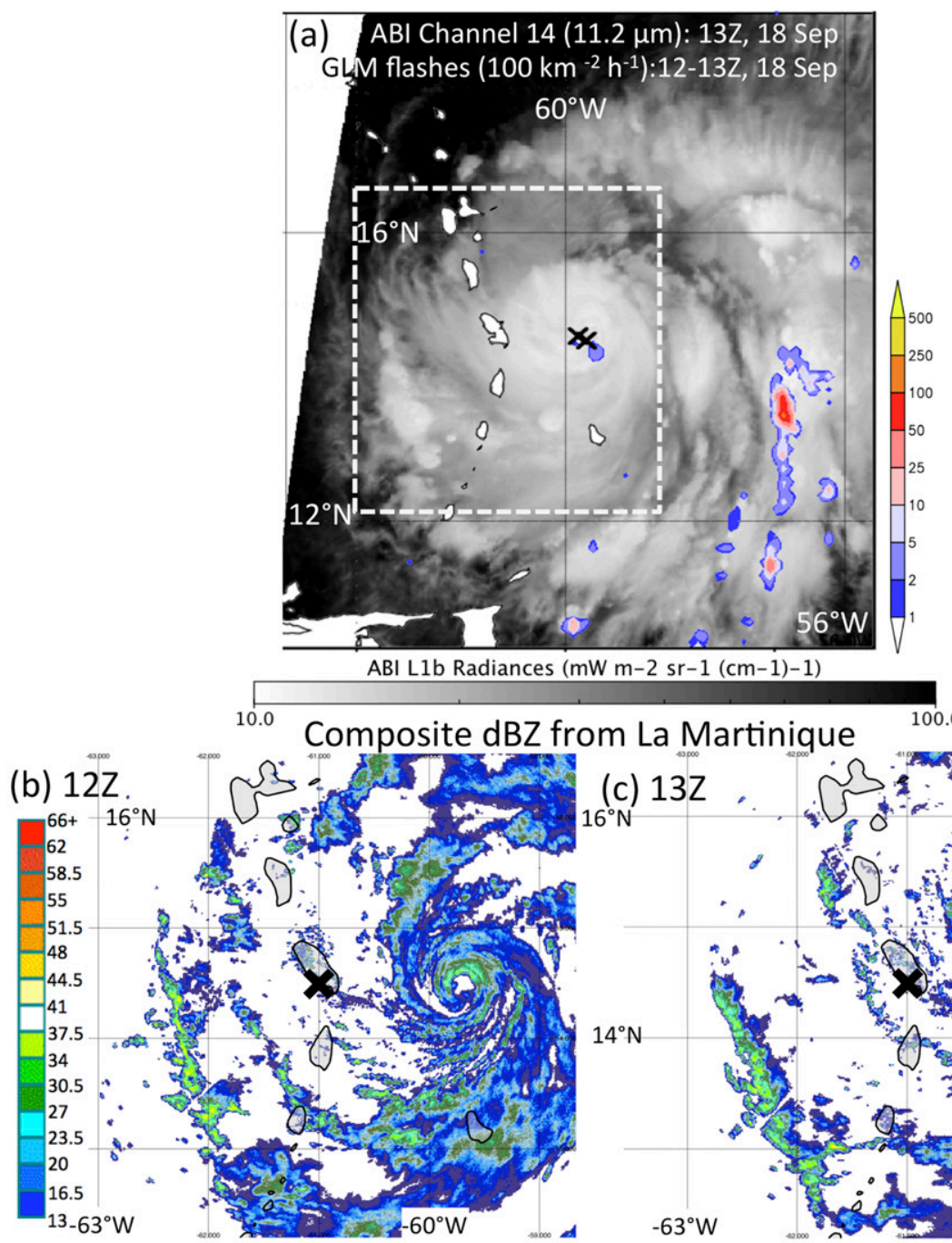

(d) $\mathrm{OHC}(\mathrm{kJ} / \mathrm{cm} 2)$ and $850-200 \mathrm{hPa}$ shear
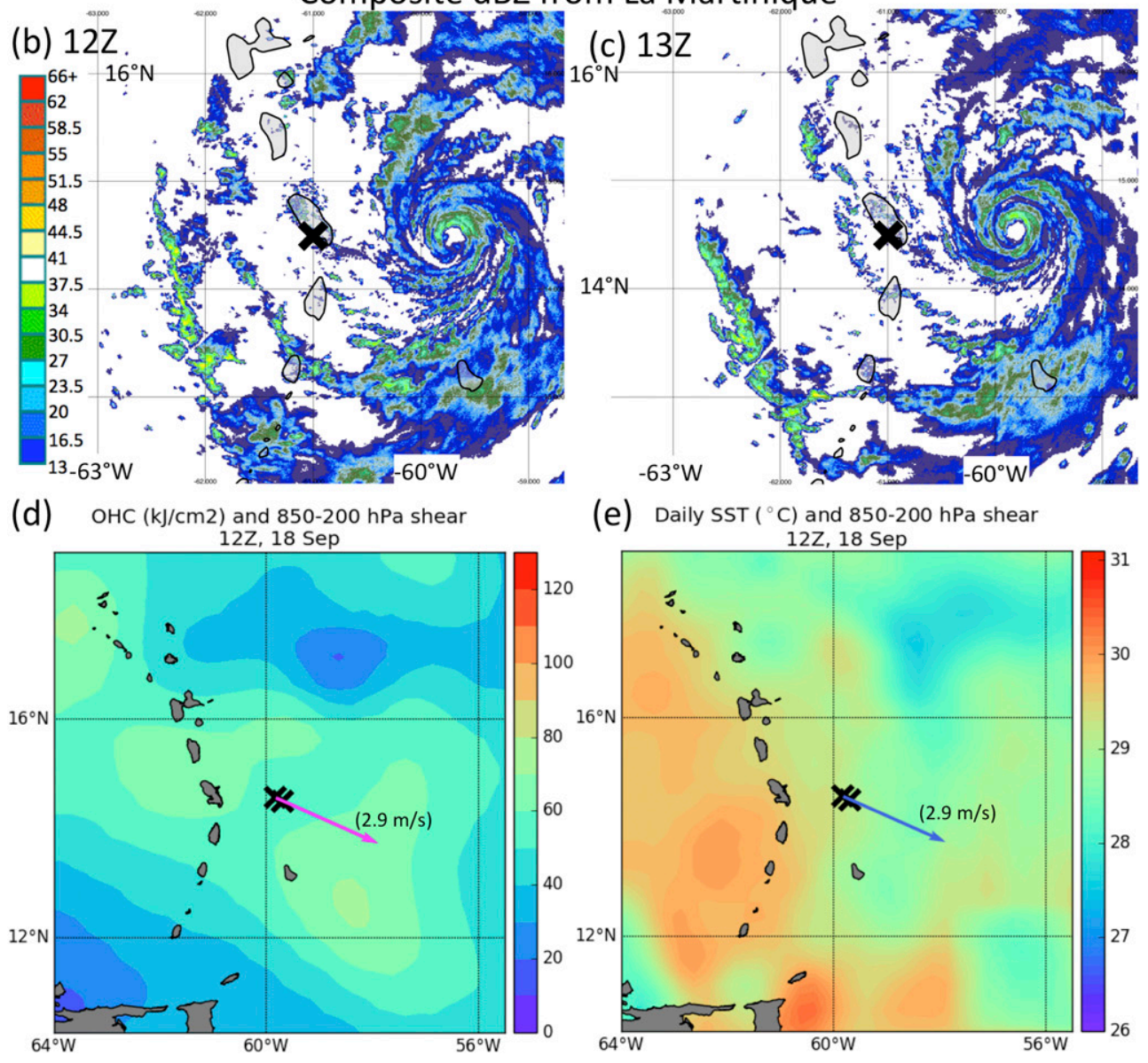

(e) Daily SST $\left({ }^{\circ} \mathrm{C}\right)$ and $850-200 \mathrm{hPa}$ shear

FIG. 7. Horizontal cross section of (a) 1200-1300 UTC 18 Sep hourly flash densities (per $100 \mathrm{~km}^{2}$, color shaded) overlaid on ABI channel $14(11.2 \mu \mathrm{m})$ radiance $\left[\mathrm{mWm}^{-2} \mathrm{sr}^{-1}\left(\mathrm{~cm}^{-1}\right)^{-1}\right.$, gray shading] at 1300 UTC 18 Sep. Composite reflectivity fields from the Météo France Doppler radar in La Martinique are shown at (b) 1200 and (c) 1300 UTC 18 Sep, with a thick black cross indicating the radar site. (d),(e) Horizontal cross sections of the $\mathrm{OHC}\left(\mathrm{kJ} \mathrm{cm}^{-2}\right)$ and the Hadley SST $\left({ }^{\circ} \mathrm{C}\right)$, respectively, overlaid with the SHIPS 850-200-hPa 
was generally weak and sporadic (Figs. 3, 8a). From this location onward, TC Maria is embedded in an environment very favorable for intensification with SST $(\mathrm{OHC})$ values commonly exceeding $29^{\circ} \mathrm{C}\left(70 \mathrm{~kJ} \mathrm{~cm}^{-2}\right)$ combined with weak deep-layer shear $\left(<3 \mathrm{~m} \mathrm{~s}^{-1}\right.$; Figs. 8d,e).

Near the time of the onset of the second intensification cycle at 0600 UTC 19 September, lightning was again tightly clustered near the storm center (Figs. 3, 4), primarily in the southern portion of the eyewall (Fig. 9a). Consistent with this, both composite radar imageries from La Martinique and La Guadeloupe indicated that the southern portion of Maria's eyewall was characterized by relatively larger reflectivities, compared to the northern eyewall (Figs. 9b,c). This suggests that even after considering the $\sim 17-\mathrm{km}$ location error of the GLM data, this observation might be valid. The sharp increase in lightning rates in the outer region documented earlier in Figs. 2 and 3 is associated with deep convective rainbands in the southeastern (rear left) quadrant, characterized by isolated $40+\mathrm{dBZ}$ echoes (Fig. 9c) and relatively lower radiance values (Fig. 9a). These lightning-active rainband cells, yet again, appear to collocate relatively well with regions of relatively higher SST and OHC values (Figs. 9d,e). The persistence of very low deep-layer shear thus far $\left(<3 \mathrm{~m} \mathrm{~s}^{-1}\right)$ accounts for the cloud pattern of TC Maria to become progressively more axisymmetric (Fig. 9a). The precipitation structure over La Guadeloupe (Fig. 9b) appears more stratiform, with maximum echoes seldom exceeding $35 \mathrm{dBZ}$, which is consistent with the dearth of lightning seen in this region (Fig. 9a).

A few hours into the second intensification cycle at 1200 UTC 19 September (Figs. 1, 2), the inner core continues to exhibit lightning concentrated near its center (Figs. 3, 4) with a slight southeastward positional shift relative to the storm center estimates (Fig. 10a). Radar imagery from both Météo France radars indicates, however, that during that $1-\mathrm{h}$ period, the northwestern portion of the eyewall exhibited the largest reflectivities, which occasionally exceeded $45 \mathrm{~dB} Z$ (Figs. 10b, c). Although this collocation disagreement between the lightning and reflectivity maxima in the inner core exceeds $17 \mathrm{~km}$, it is likely that taking the GLM location error into account could potentially help reduce this difference. The outer-region lightning at this time (Figs. 2, 3) is, again, associated with deep convection in the southeastern quadrant of the TC, with some cells reaching maximum reflectivities near $40 \mathrm{dBZ}$ (Fig. 10b). Compared to $6 \mathrm{~h}$ earlier (Fig. 10a), the areal coverage of the central dense overcast cloud shield shrunk noticeably in the ABI imagery (Fig. 10a), while the outgoing radiance values in the inner core showed slightly lower values (indicative of colder cloud tops). Together with the increase of inner-core flash rates documented earlier (Figs. 2c, 3c), this would be supportive of a gradual strengthening of the convection in the eyewall of Maria (MacGorman and Rust 1998; Kelley et al. 2004; Fierro et al. 2011; Fierro and Mansell 2018). Maria's continuing intensification into a category 5 storm stems from continuing favorable conditions for intensification with very weak deep-layer shear $\left(<2 \mathrm{~m} \mathrm{~s}^{-1}\right)$ and high SSTs $\left(30^{\circ} \mathrm{C}\right.$; Figs. 10d,e). The lightning-active regions in the outer bands to the south, again, collocate well with regions of relatively higher SSTs and OHC (Figs. 10d,e).

A few hours after reaching its maximum intensity near 0600 UTC 20 September (Figs. 1, 2), Maria underwent an eyewall replacement cycle, as evidenced by a concentric eyewall configuration in the radar sweeps (Figs. 11b,c). This eyewall replacement cycle resulted in the slow weakening of Maria until it made landfall in Puerto Rico at about 1000 UTC 20 September (Figs. 1, 2). As documented by several studies, eyewall replacement cycles often precede TC weakening due to the expansion of the RMW and changes in the radial pressure gradient in the inner core (Willoughby et al. 1982; Sitkowski et al. 2012; Kossin 2015). This double eyewall configuration is associated with an increase of the areal coverage of the central dense overcast in the ABI imagery (cf. Fig. 10a and Fig. 11a), consistent with previous findings (e.g., Willoughby et al. 1982; Sitkowski et al. 2011; Kossin and Sitkowski 2012). During this period, lightning in the inner core was occasionally seen ahead of the storm center (Fig. 11a) near the outer eyewall (Figs. 11b,c). Based on the storm

\footnotetext{
$\longleftarrow$

shear vector at 1200 UTC 18 Sep. Interpolated storm centers from the NHC best track are shown by black crosses in (a), (d), and (e) at the beginning and end of the 1-h lightning accumulation period (note: best track estimate may differ slightly from ABI and radar imagery eye center location). For reference, the domain covered by the radar imageries in La Martinique in (b) and (c) is shown as a dashed white rectangle in (a). Subsequent Figs. 8-10 include radar imageries of Météo France from either La Guadeloupe or La Martinique based on availability, data quality, and coverage of the lightning-active portion(s) of the TC. La Guadeloupe radar domain coverage is shown by a yellow dashed rectangle in the ABI imagery, when applicable.
} 

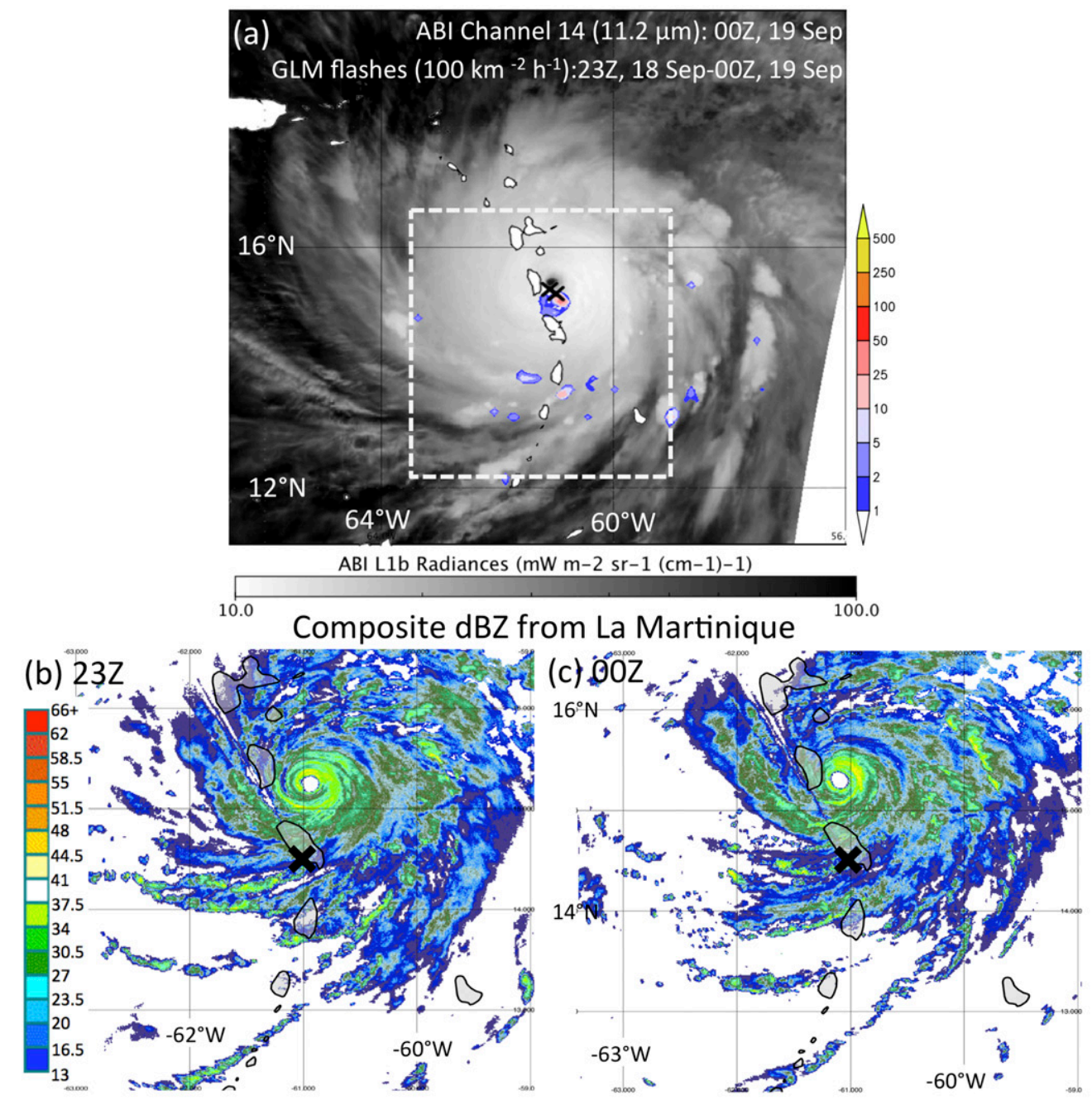

(d) OHC (kJ/cm2) and 850-200 hPa shear
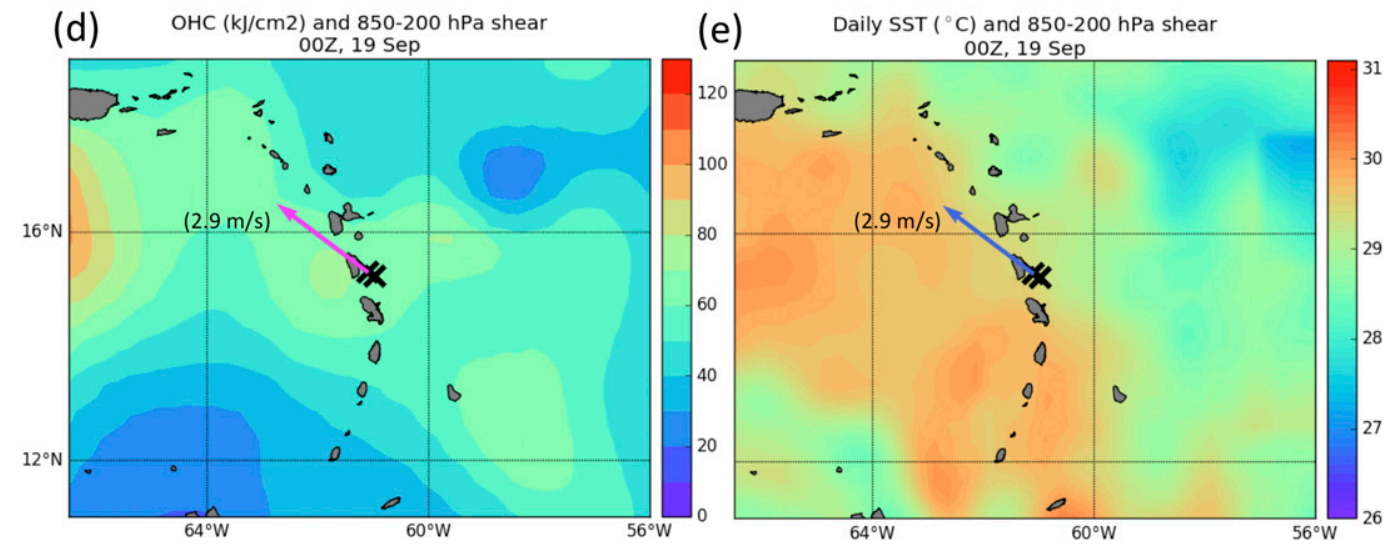

FIG. 8. As in Fig. 7, but between 2300 UTC 18 Sep and 0000 UTC 19 Sep.

center locations at 0500 and 0600 UTC 20 September in Fig. 10a and the lightning totals in Fig. 2a, it appears that the arc-shaped lightning contours near the inner core are likely associated with electrified convection occurring near the beginning of the 1-h interval (i.e., 0500 UTC 20 September). This is another particular instance where the $17-\mathrm{km}$ average location error of the GLM documented earlier renders such a precise 

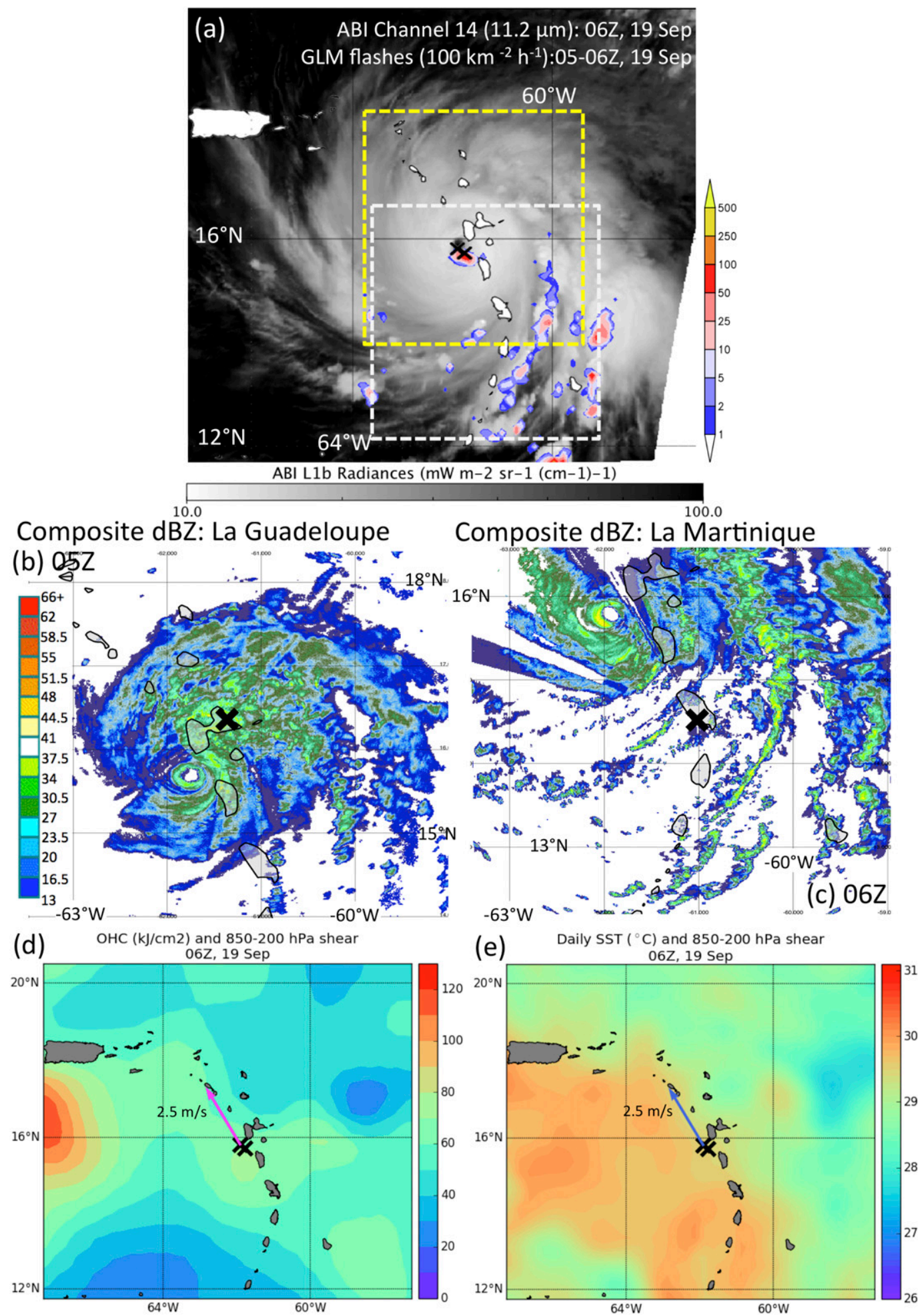

FIG. 9. As in Fig. 7, but between 0500 and 0600 UTC 19 Sep.

diagnosis difficult. As documented earlier in Figs. 2 and 3, the bulk of Maria's lightning at the time was found in the outer region, which again was associated with deep convection in its southeastern quadrant (Fig. 11a) over regions of relatively higher SSTs and OHC (Figs. 11d,e). 


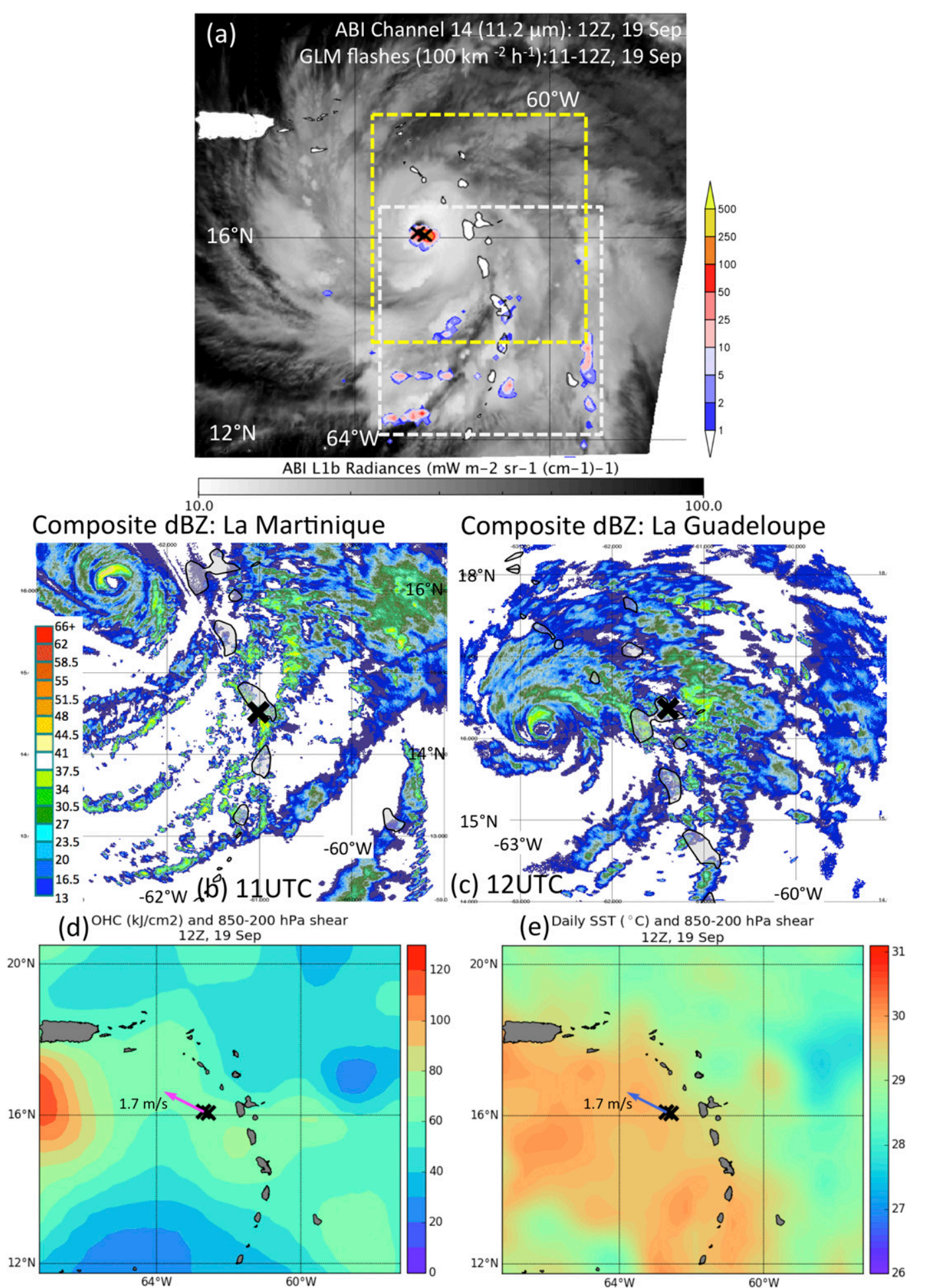

FIG. 10. As in Fig. 7, but between 1100 and 1200 UTC 19 Sep.

Between 0600 UTC 20 September and the time when the WSR-88D radar in Puerto Rico was destroyed by the hurricane shortly before 2000 UTC 20 September, the vast majority of the lightning, again, occurred in the outer region (Figs. 2,3) in the southeast quadrant (not shown). 


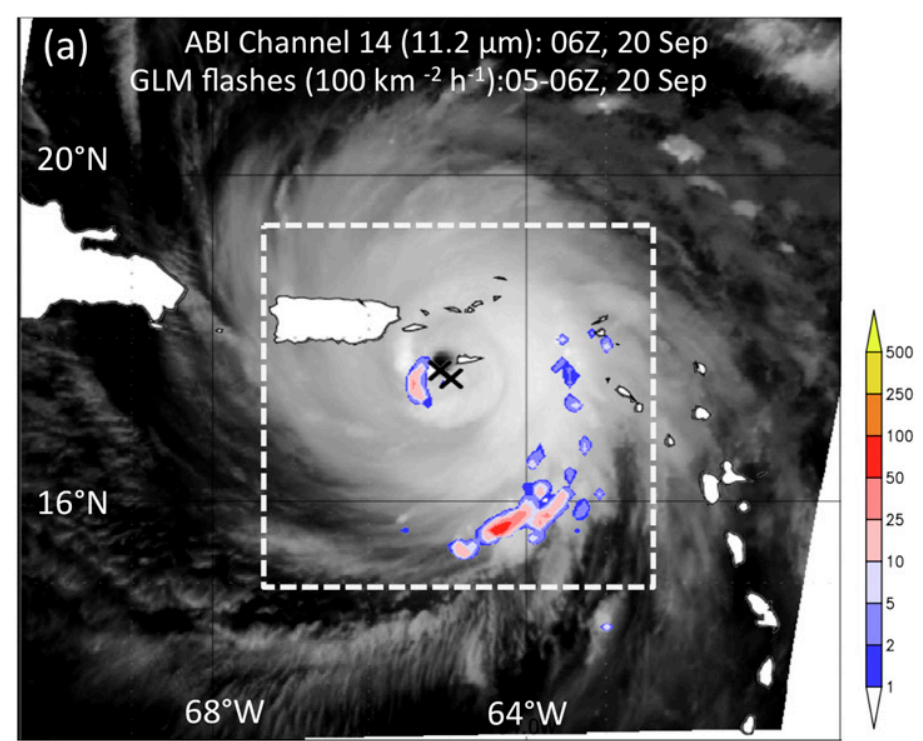

ABI L1b Radiances (mW m-2 sr-1 (cm-1)-1)
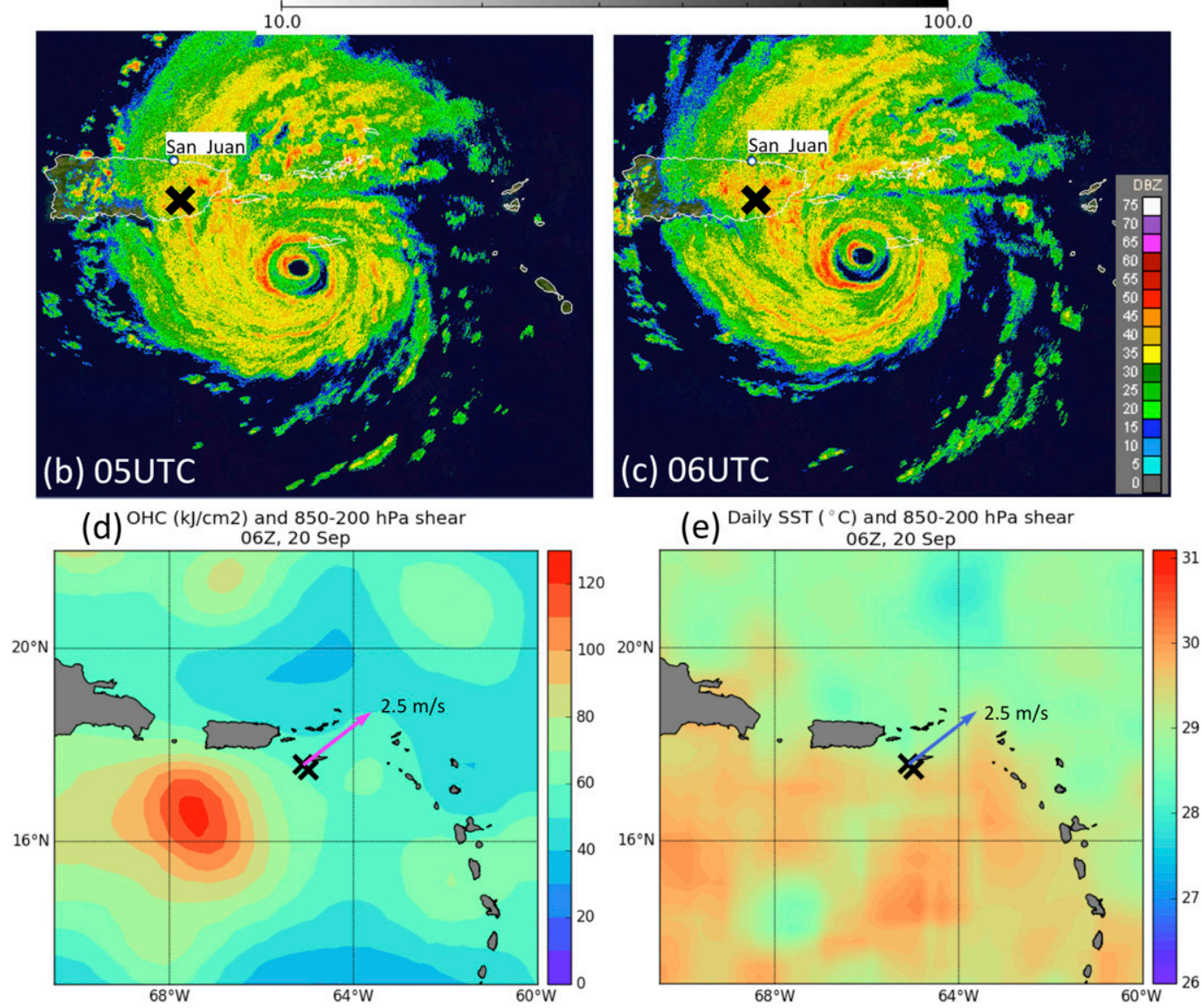

FIG. 11. As in Fig. 7, but between 0500 and 0600 UTC 20 Sep and for composite reflectivity imageries from the Cayey radar site (TJUA), the location of which is shown by a thick black cross in (b) and (c). The radar imageries are courtesy of B. McNoldy, University of Miami, Rosenstiel School (http://andrew.rsmas.miami.edu/bmcnoldy/ tropics/radar/). 
In summary, this analysis showed that during the time period considered, the lightning in the outer region of Maria was primarily confined in the southeast quadrant in regions of relatively higher SSTs and OHC. This behavior is consistent with the simulated rainband lightning in idealized (Fierro et al. 2007; Fierro and Mansell 2017, 2018) and real case studies (Fierro and Reisner 2011; Fierro et al. 2015). As hypothesized by some of these modeling studies, in a large-scale environment favorable for TC development (low shear, high sea surface temperatures), the warm air advection from lower latitudes in that quadrant (in the Northern Hemisphere) may be more favorable for the systematic development of thunderstorms (Williams and Renno 1993) through enhanced isentropic ascent (Callaghan and Tory 2014, their Fig. 10). This analysis also indicated that, at most times, lightning was primarily located in the southern portion of the eyewall, which contrasts with the modeling studies of Fierro and Mansell (2017, 2018), who found that in steady-state or intensifying TCs in an environment at rest (i.e., no ambient wind shear), the preferred location for lightning occurrence was in the northwest quadrant. The persistence of very weak deeplayer shear $\left(<3 \mathrm{~m} \mathrm{~s}^{-1}\right)$ cannot explain alone why the inner-core lightning in this TC preferentially occurred in the southwest (Figs. 5a,b), though it is unknown if the GLM location errors that were present during its testing phase in 2017 may reveal an inner-core azimuthal pattern that is more consistent with previous studies.

\section{c. Brief comparisons with WWLLN}

Several previous studies employed the WWLLN to better understand the association between lightning flash rates and TC intensity change. The WWLLN has the longest record of time-continuous global lightning, making it ideal for TC studies; however, since it is a very low-frequency network, the detection efficiency of WWLLN for IC flashes $(<10 \%)$ is notably lower than GLM $(\sim 70 \%-90 \%)$. In contrast to CG flashes, total lightning (ICs + CGs) was shown to better correlate with storm-scale bulk properties, such as graupel or updraft volumes, within convective storms (MacGorman et al. 1989; Carey and Rutledge 1996; Wiens et al. 2005; Kuhlman et al. 2006; Fierro et al. 2006) and TCs (Fierro et al. 2015; Fierro and Mansell 2017, 2018). Because ICs outnumber CGs by an average ratio of $3: 1$ in nonsevere storms (e.g., Boccippio et al. 2001; Schultz et al. 2011; Medici et al. 2017), it is relevant to determine preliminarily how the hourly rates from the WWLLN (primarily CG) compare to the GLM (total lightning). Such systematic comparisons are warranted to examine whether a simple scaling between the two datasets is possible or if lightning characteristics documented by WWLLN will translate to similar features captured by GLM.

Table 1 summarizes the number of WWLLN strokes and GLM events, groups, and flashes during the 60-h analysis period. The WWLLN counts differed most significantly from the GLM events (from approximately two to three orders of magnitude) and were closest to the GLM flashes (one order of magnitude or less). Overall, the GLM captured about 4 times as many flashes as WWLLN within $500 \mathrm{~km}$ of Hurricane Maria during the analysis period. Around 30 times more flashes were detected by GLM in the inner core over this entire 60-h period, a stark contrast to the outer region, which only saw about 3 times as many flashes in GLM, compared to WWLLN. This may suggest that more CG flashes occurred in the outer region.

A direct comparison between Figs. 12 and 2c reveals overall similar patterns in the outer-region lightning flashes, but differences in the inner-core hourly flash rates with respect to storm intensity. The initial innercore CG lightning peak at 1700 UTC 18 September, $7 \mathrm{~h}$ prior to the end of the first intensification cycle, was seen by WWLLN but is absent in GLM total lightning data, which hints at a rather steady, relatively weak total lightning activity. The inner-core GLM flash rate maxima that occurred near the beginning of the first 6-h weakening period (0200 UTC 19 September) was captured by the WWLLN, though with much fewer flashes. During the second intensification cycle, the GLM registered peak flash rates in the inner core at 1000 UTC 19 September, while those recorded by WWLLN occurred slightly later at 1600 UTC 19 September. The differences in the timing of peak lightning activity during the intensification period on 19 September may indicate that the dominant type of lightning (CG or IC) changed: weak CG or IC flashes may have occurred more frequently early in this intensification period, as evidenced by high (low) hourly flash rates for GLM (WWLLN), which transitioned to a larger fraction of CG flashes toward the end. Similar to the GLM, the WWLLN captured a semiregular diurnal variability in outer-region lightning flash rates, peaking around 1200 UTC each day.

Despite differences in the total flash rates between the two observing platforms, some correlation between the WWLLN and GLM flash rates does exist. Figure 13 shows the (Pearson's) correlations between the WWLLN and the three GLM lightning products (events, groups, and flashes) for the inner core (top) and outer region (bottom) normalized by their respective maximums throughout the 60-h analysis period. WWLLN strokes were weakly correlated with GLM events and exhibited the largest correlation with GLM flashes. As expected 
TABLE 1. Number of WWLLN strokes and GLM events, groups, and flashes for the regions of the TC during the 60-h analysis period beginning at 1200 UTC 18 Sep, with the ratio between the two lightning platforms (GLM to WWLLN) indicated in parentheses for each of the three GLM products.

\begin{tabular}{lcccc}
\hline \hline & WWLLN & \multicolumn{3}{c}{ GLM (GLM to WWLLN ratio) } \\
\cline { 2 - 5 } & Strokes & \multicolumn{1}{c}{ Events } & Groups & Flashes \\
\hline Inner core & 668 & $480723(719.6)$ & $170363(225.0)$ & $21021(31.5)$ \\
Outer region & 20044 & $2267882(113.1)$ & $717624(35.8)$ & $58718(2.9)$ \\
Total & 20712 & $2748605(132.7)$ & $887987(42.9)$ & $79739(3.8)$ \\
\hline
\end{tabular}

based on Fig. 12, the correlation coefficient between the two datasets was more robust in the outer region, reaching values of $r=0.70(r=0.75)$ when analyzing the hourly (6 hourly) data (Fig. 13f). The inner-core flash correlations were notably smaller, with $r=0.33$ $(r=0.51)$ in the hourly (6 hourly) analysis (Fig. 13c). Because the GLM senses the optical emission from a lightning flash, while the WWLLN measures the broadband electromagnetic impulses emitted by lightning flashes within a very low-frequency band, many loweramplitude flashes (such as ICs) are missed by WWLLN. The smaller correlations in the inner core may be further indication of different lightning strengths (peak current) and types occurring near the TC center.

To complement the temporal comparisons, spatial locations of WWLLN strokes are shown in Fig. 14 for the time periods highlighted for the GLM in Figs. 7a, 8a, 9a, and 10a. Comparing Fig. 14a with the GLM flash densities between 1200 and 1300 UTC 18 September
(Fig. 7a), it becomes obvious that the WWLLN does, overall, remarkably well at capturing the spatial distribution of outer-region flashes but fails to record inner-core flashes seen by the GLM. The same spatial patterns exist from 2300 UTC 18 September to 0000 UTC 19 September (Figs. 14b, 8a); however, the WWLLN begins to match the GLM spatially in the inner core during the beginning of the second intensification period around 0500 UTC 19 September (Figs. 14c, 9a). By 1100 UTC 19 September, the large GLM inner-core flash density corresponds to a significant number of WWLLN strokes (Figs. 14d, 10a). The spatial patterns observed between the two networks suggests that WWLLN captures the overall distribution of lightning relatively well, particularly in the outer region; however, more work needs to be done to more accurately evaluate and understand the discrepancies in inner-core lightning. It is hypothesized that the ratio of IC to CG flashes differs between the two TC regions, such that the inner

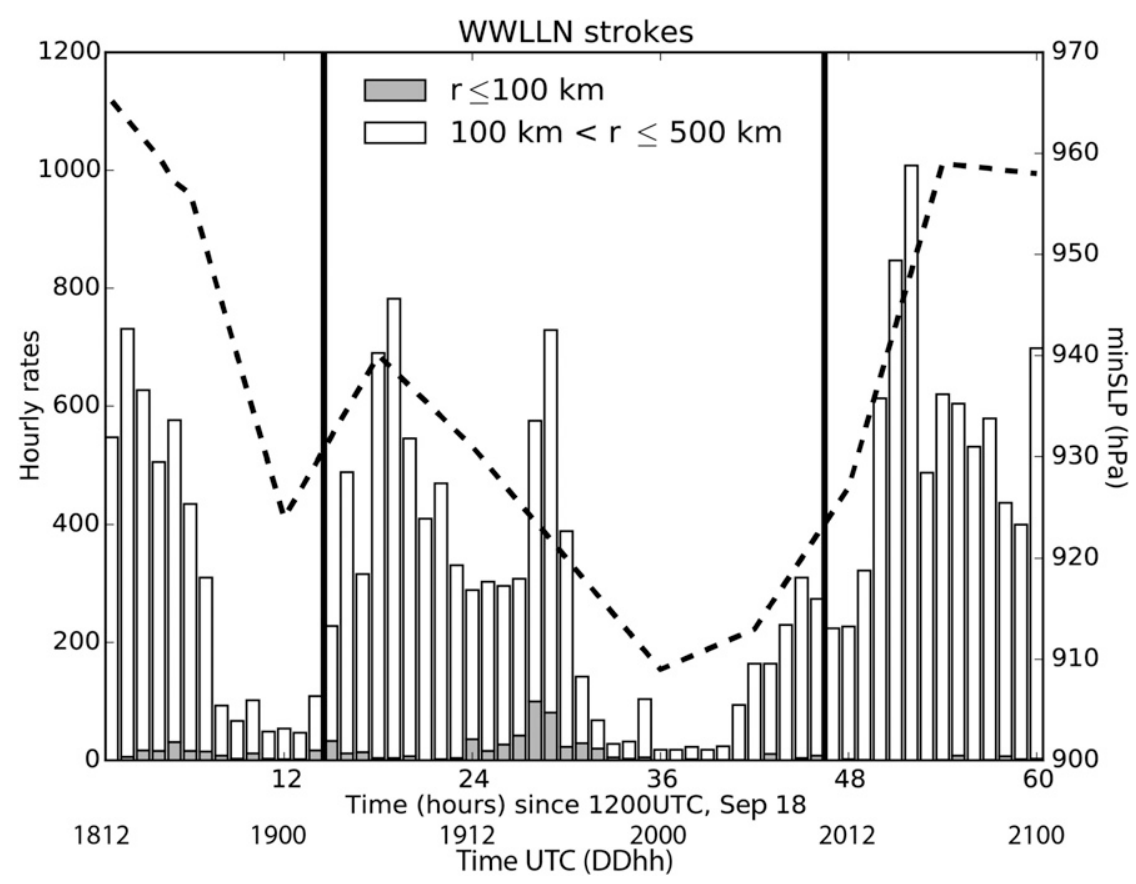

FIG. 12. As in Fig. 2, but for WWLLN hourly strokes. 

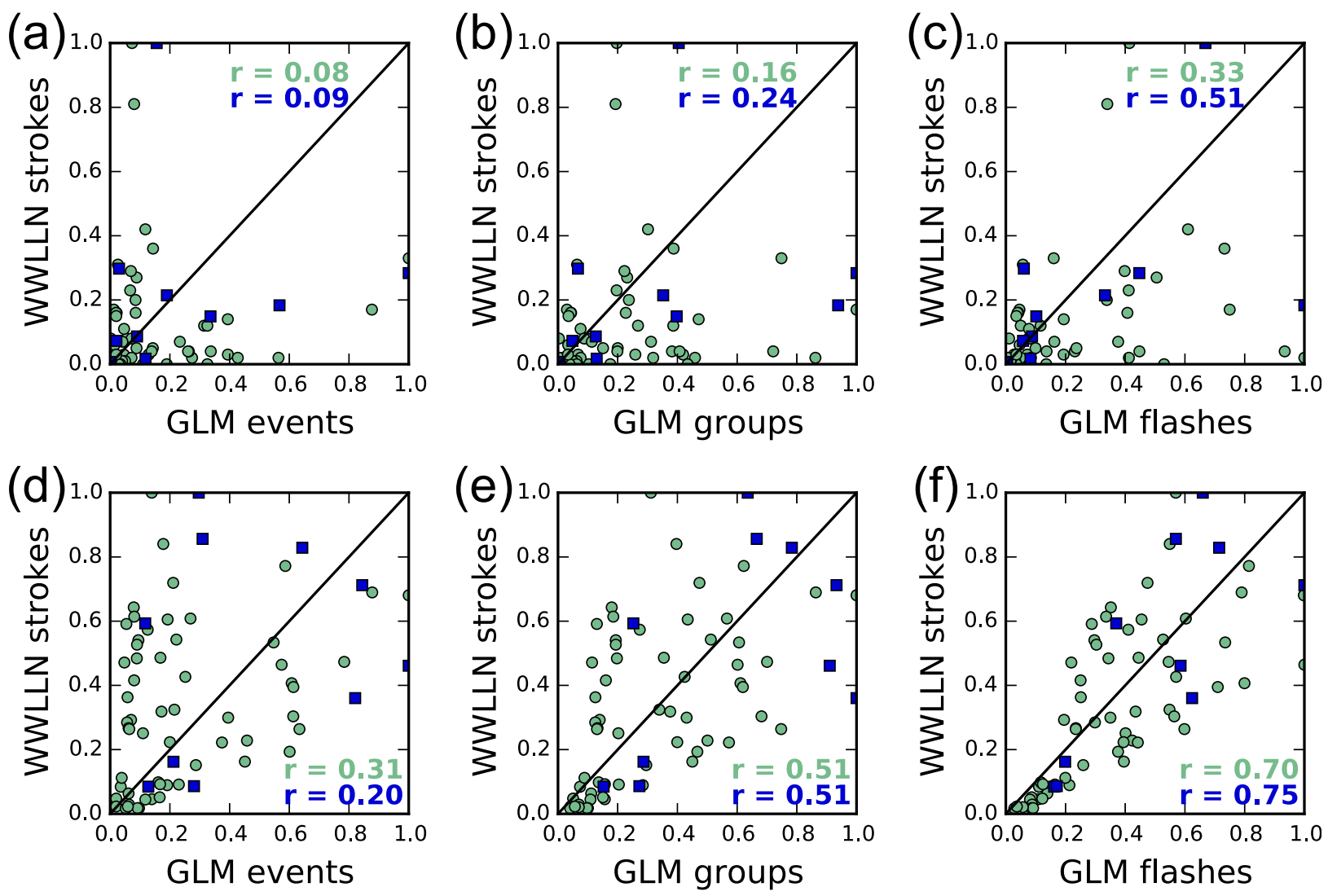

FIG. 13. Normalized scatterplots of the (top) inner core and (bottom) outer region hourly (green) and 6-hourly (blue) lightning rates recorded by GLM ( $x$ axis) and WWLLN ( $y$ axis) during the 60-h period of interest beginning at 1200 UTC 18 Sep. WWLLN comparisons were made with GLM (a),(d) events, (b),(e) groups, and (c),(f) flashes. The black line shows a 1:1 relationship (i.e., exactly similar), and the respective Pearson correlation coefficients are displayed for both the hourly and 6-hourly data.

core experiences a larger fraction of IC flashes. This may suggest that the previous WWLLN studies could have been observing CG flash correlations to intensity change, and that IC flashes may show a different relationship. Thus, translation of inner-core WWLLN studies to GLM should be taken cautiously until further research is done. The utilization of the WWLLN and GLM in unison will help advance the understanding of TC lightning and its relationship to intensity changes.

\section{Discussion and conclusions}

This study provides a glance of the evolution of total lightning activity with a major hurricane undergoing several distinct intensification cycles. Toward this goal, three separate lightning metrics provided by the GLM instrument were investigated, which also provides a broad initial overview and an appreciation of their differences/similarities. The total lightning activity in two key regions of the TC, namely, the inner core $(r<$ $100 \mathrm{~km})$ and outer region $(100<r \leq 500 \mathrm{~km})$, were analyzed first to identify potential linkages between their trends and intensity fluctuations of the TC. Although it is relevant to stress that the GLM data used in this study are considered preliminary and contain average location errors on the order of $\sim 17 \mathrm{~km}$ for the time period and domain considered, this would not affect the salient conclusions of this study.

During the analysis period beginning 1200 UTC 18 September and ending 0000 UTC 21 September, Hurricane Maria underwent two distinct intensification and weakening cycles, respectively. Although not covering the entirety of its pressure drop, the first, more prominent, intensification cycle is reasonably well captured by this period. Overall, the beginning of each intensification cycle was characterized by an increase in lightning in the outer region, consistent with DeMaria et al. (2012) and $\mathrm{Xu}$ et al. (2017). Inner-core lightning increases occurred after the end of the first and at the beginning of the second intensification cycle, of which the latter agrees with earlier findings for some TCs (Molinari et al. 1994, 1999; Stevenson et al. 2018). After reaching its 
(a) WWLLN strokes $1200-1300$ UTC 18 Sep

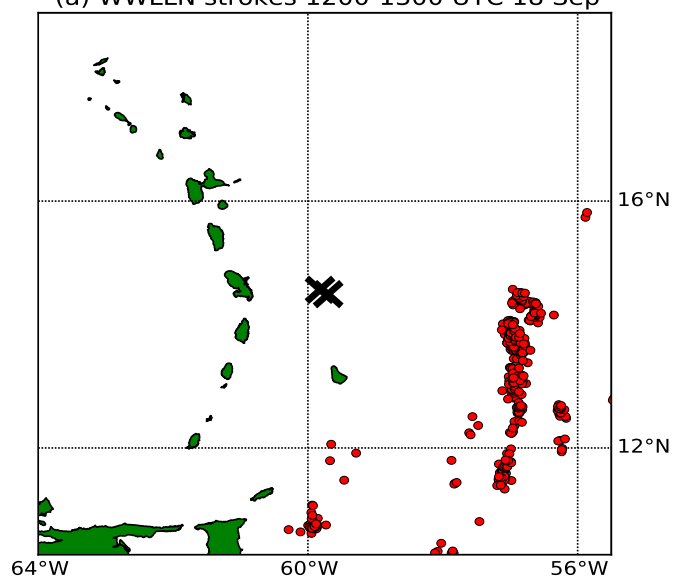

(c) WWLLN strokes 0500-0600 UTC 19 Sep

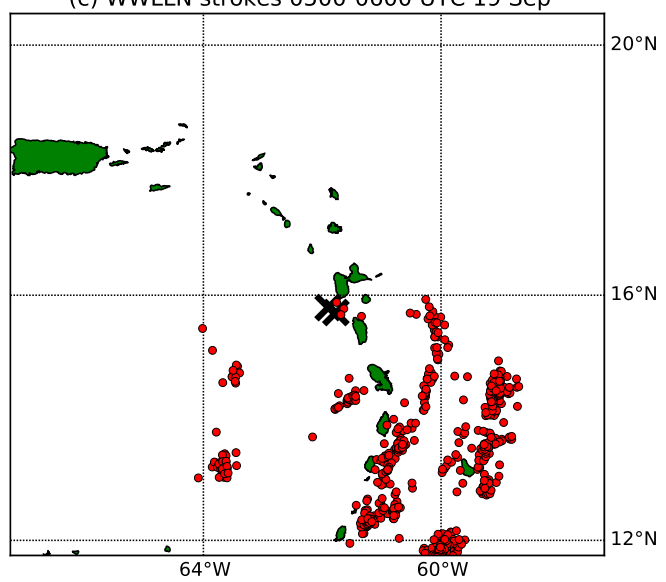

(b) WWLLN strokes 2300-0000 UTC 18-19 Sep

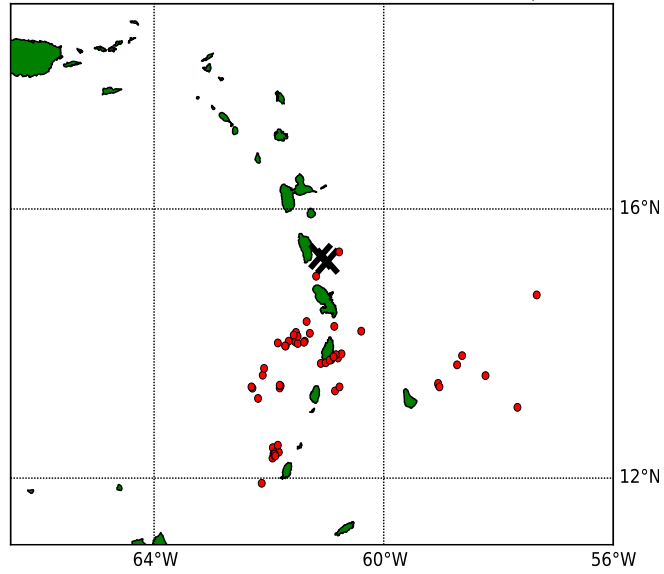

(d) WWLLN strokes 1100-1200 UTC 19 Sep

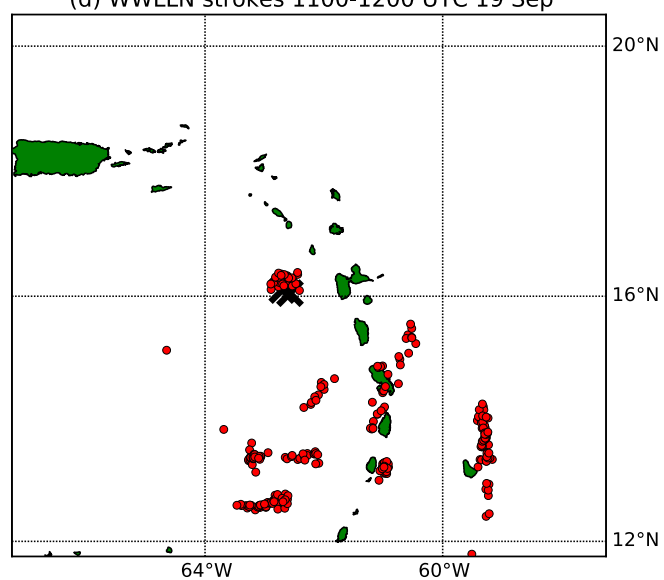

FIG. 14. Geographical locations of recorded WWLLN strokes (red circles) at hours chosen to match the first panel of Figs. 7-10. The hourly WWLLN data correspond to the following times: (a) 1200-1300 UTC 18 Sep, (b) 2300-0000 UTC 18/19 Sep, (c) 0500-0600 UTC 19 Sep, and (d) 1100-1200 UTC 19 Sep. The TC center locations for the beginning and end of the hour are also shown by black crosses.

peak intensity at about 1000 UTC 20 September, Maria's gradual weakening was associated with virtually no lightning in its inner core and abundant lightning in its outer region. During this weakening period, the outer region lightning increased abruptly from (hourly) flash rates $<100$ to rates exceeding 1000 and then maintained those high rates. Storm-centered Hovmöller diagrams of each of the GLM lightning metrics revealed that the inner-core lightning was chiefly confined within a $50-\mathrm{km}$ radius from the storm center and highlighted the relative minimum in total lightning associated with the inner-band stratiform precipitation at the periphery of the eyewall.

Bootstrapped correlation statistics with 1000 random samples showed that, overall, the most robust relationship between lightning and storm intensity was obtained between inner-core rates (particularly groups and flashes) and maxWSP with $R \sim 0.4-0.5$. Additional noteworthy associations were obtained between the flash rates in the outer region and either minSLP or maxWSP. Interestingly, storm total lightning rates exhibited, overall, insignificant to marginal correlations with storm intensity. The correlations statistics for the future 6-hourly changes in either minSLP or maxWSP in the inner core was generally negative, and it was positive for the outer region, suggesting again some agreement with DeMaria et al. (2012).

This broader, TC-scale analysis of the lightning was followed by a more detailed view of the spatial association among total lightning, precipitation structures, local environment (shear, SST, and OHC) and cloud depth/morphologies (outgoing IR radiance). The vast majority of the lightning in the outer region occurred in the southeastern quadrant, a behavior consistent with recent modeling studies of electrification within TCs, either idealized or focusing on real cases. These lightning-active regions in the outer band were systematically collocated 
with regions of relatively higher SST and OHC. In the inner core, lightning was most frequently seen in the southern eyewall, with the exception of occasional weaker bursts in the northwest quadrant of a secondary eyewall as Maria underwent an eyewall replacement cycle prior to making landfall in Puerto Rico. These preferential locations of inner lightning cannot be explained by deep-layer shear alone, which remained weak $\left(<3 \mathrm{~m} \mathrm{~s}^{-1}\right)$ throughout the analysis period. The combination of the location errors with the 2017 GLM dataset, the small uncertainty errors of the ground-based networks it was compared to, the likely small uncertainties in the preliminary track, and an overall extremely small eye diameter $(<\sim 25 \mathrm{~km})$, where a good portion of the lightning was occurring, rendered it challenging to confidently determine whether this atypical inner-core lightning pattern was real or spurious. Given, however, that several previous studies have looked at matured lightning datasets over many TCs and consistently found that either deep-layer shear and/or TC motion controlled the preferential location of the lightning in the inner core, this would suggest that the inner-core quadrant distribution of the GLM obtained herein contains nonnegligible errors. On the other hand, Fierro et al. (2011) found that in contrast to CGs, IC flashes could be used to track the revolution of individual convective events around the eyewall of Hurricane Rita (2005), which featured comparable intensity and eyewall diameter to TC Maria during the period investigated. Complete revolutions of individual IC flash clusters around the eyewall in Rita were generally on the order of 15-25 min. Given that upper-level IC flashes are more readily detected than low-level flashes (mainly CGs) by optical instruments due to an increasing (cold) cloud depth (Yoshida et al. (2009), it is thus possible that the flash density maximum in the southern eyewall of TC Maria may be associated with the rotation of IC flashes from electrified convection initially developing in the frontright quadrant of the TC. This appears consistent with the later analysis with WWLLN CG data, which shows flashes clustering more systematically near the front-right quadrant of the TC and with the inner core showing a noticeably larger ratio of IC to CG.

Climatological averages of the weekly SSTs and deeplayer shear derived from the 6-hourly SHIPS data revealed that over the study region, the environment in which TC Maria intensified into a category 5 storm was unusually favorable with SSTs noticeably above average $\left(\right.$ by $1^{\circ}-3^{\circ} \mathrm{C}$ ) and deep-layer shear below average (by as much as a factor of 2).

A last aspect of this study was a brief comparison of the GLM total lightning flashes with those detected by the very low-frequency WWLLN network, which primarily consist of CG flashes. Direct comparisons between the respective evolutions of inner-core hourly flash rates revealed some noteworthy differences in terms of 1) the ratio between GLM and WWLLN rates often exceeding two orders of magnitude and 2) the respective timing/presence of lightning bursts with respect to intensity fluctuations. WWLLN detected an inner-core CG burst a few hours into the first intensification cycle, while GLM revealed a relatively steady and weak total lightning activity at that time. WWLLN detected two additional distinct CG bursts right after the end of the first intensification cycle and several hours into the second intensification cycle-both of which were also present in the GLM total lightning evolution, with slight time differences. Akin to GLM, WWLLN showed lightning in the outer region to be associated with deep moist convection in the southeastern quadrant of the TC.

The findings presented herein illustrate that continuous-in-time, satellite-based total lightning has provided a promising new tool for studying TCs. Although the data analysis is suggestive of at least some agreement with past observational and modeling studies, general statements cannot be made from a single case. It is thus anticipated that forthcoming observational and modeling studies focusing either on Maria or on other TCs during the 2017 Atlantic season (e.g., Irma, Harvey, or Jose) will help to further augment our understanding of the complex relationship(s) existing among total lightning, storm intensity, precipitation fields, and convective evolution.

Acknowledgments. Funding was provided by NOAA/ Office of Oceanic and Atmospheric Research under NOAA-University of Oklahoma Cooperative Agreement NA11OAR4320072, U.S. Department of Commerce. This work was further supported by the GOES-R program by Grants NOAA-NWS-NWSPO2016-2004610 and NOAA-OAR-CIPO-2014-2003893. The data processing was conducted on the NOAA HPC "Jet" resources housed in Boulder, Colorado, and on computer resources provided by the Oklahoma Supercomputing Center for Education and Research (OSCER) hosted at the University of Oklahoma. The authors thank Météo France for providing the radar reflectivity data for La Martinique/La Guadeloupe and Kristin Calhoun at the Cooperative Institute for Mesoscale Meteorological Studies, University of Oklahoma, for providing the GOES-R datasets (ABI and GLM). The authors are also grateful to Brian McNoldy, University of Miami, Rosenstiel School, for archiving the radar imageries of tropical cyclones and to Erik Rasmussen for providing useful guidance with the QGIS software. The authors thank Edward Mansell for providing insightful comments on an earlier version of this 
manuscript and for providing guidance with Fortran to compute the shear relative quadrants. Thanks also go out to Paul Reasor, Robert Rogers, Bradley Klotz, and Neal Dorst for providing useful insights on the available aircraft datasets for this tropical cyclone. We also would to express our gratitude to Douglas Mach (USRA) and Katrina Virts (NASA) for computing the location accuracies for the GLM data used in this analysis. Last, the authors would like to express their gratitude to one anonymous reviewer, John Knaff, and Mark DeMaria for their insightful comments and suggestions, which helped improve the quality of the manuscript.

\section{REFERENCES}

Abarca, S. F., K. L. Corbosiero, and D. Vollaro, 2011: The World Wide Lightning Location Network and convective activity in tropical cyclones. Mon. Wea. Rev., 139, 175-191, https://doi.org/10.1175/2010MWR3383.1.

Anthes, R. A., 2003: Hot towers and hurricanes: Early observations, theories, and models. Cloud Systems, Hurricanes, and the Tropical Rainfall Measuring Mission (TRMM)-A Tribute to Dr. Joanne Simpson, Meteor. Monogr., No. 51, Amer. Meteor. Soc., 139-148, https://doi.org/10.1175/00659401(2003)029<0139:CHTAHE >2.0.CO;2.

Black, R. A., and J. Hallett, 1999: Electrification of the hurricane. J. Atmos. Sci., 56, 2004-2028, https://doi.org/10.1175/15200469(1999)056<2004:EOTH >2.0.CO;2.

Boccippio, D. J., K. L. Cummins, H. J. Christian, and S. J. Goodman, 2001: Combined satellite- and surface-based estimation of the intracloud-cloud-to-ground lightning ratio over the continental United States. Mon. Wea. Rev., 129, 108-122, https://doi.org/10.1175/1520-0493(2001)129<0108: CSASBE $>2.0 . \mathrm{CO} ; 2$.

Bovalo, C., C. Barthe, N. Yu, and N. Bègue, 2014: Lightning activity within tropical cyclones in the south west Indian Ocean. J. Geophys. Res. Atmos., 119, 8231-8244, https://doi.org/ 10.1002/2014JD021651.

Brooks, I. M., C. P. R. Saunders, R. P. Mitzeva, and S. L. Peck, 1997: The effect on thunderstorm charging of the rate of rime accretion by graupel. Atmos. Res., 43, 277-295, https://doi.org/ 10.1016/S0169-8095(96)00043-9.

Callaghan, J., and K. Tory, 2014: On the use of a system-scale ascent/descent diagnostic for short-term forecasting of tropical cyclone development, intensification and decay. Trop. Cyclone Res. Rev., 3, 78-90.

Carey, L. D., and S. A. Rutledge, 1996: A multiparameter radar case study of the microphysical and kinematic evolution of a lightning producing storm. Meteor. Atmos. Phys., 59, 33-64, https://doi.org/10.1007/BF01032000.

Cecil, D. J., and E. J. Zipser, 2002: Reflectivity, ice scattering, and lightning characteristics of hurricane eyewalls and rainbands. Part II: Intercomparison of observations. Mon. Wea. Rev., 130, 785-801, https://doi.org/10.1175/1520-0493(2002)130<0785: RISALC $>2.0 . C O ; 2$.

_ — _ and S. W. Nesbitt, 2002: Reflectivity, ice scattering, and lightning characteristics of hurricane eyewalls and rainbands. Part I: Quantitative description. Mon. Wea. Rev., 130, 769-784, https://doi.org/10.1175/1520-0493(2002)130<0769: RISALC $>2.0 . \mathrm{CO} ; 2$.
Christian, H. J., and Coauthors, 1999: The Lightning Imaging Sensor. Proc. 11th Int. Conf. on Atmospheric Electricity, Guntersville, AL, International Commission on Atmospheric Electricity, 746-749.

Chronis, T., L. D. Carey, C. J. Schultz, E. V. Schultz, K. M. Calhoun, and S. J. Goodman, 2015: Exploring lightning jump characteristics. Wea. Forecasting, 30, 23-37, https://doi.org/ 10.1175/WAF-D-14-00064.1.

Corbosiero, K. L., and J. Molinari, 2002: The effects of vertical wind shear on the distribution of convection in tropical cyclones. Mon. Wea. Rev., 130, 2110-2123, https://doi.org/ 10.1175/1520-0493(2002)130<2110:TEOVWS > 2.0.CO;2.

Cummings, J. A., 2005: Operational multivariate ocean data assimilation. Quart. J. Roy. Meteor. Soc., 131, 3583-3604, https:// doi.org/10.1256/qj.05.105.

DeMaria, M., and J. Kaplan, 1994: A Statistical Hurricane Intensity Prediction Scheme (SHIPS) for the Atlantic basin. Wea. Forecasting, 9, 209-220, https://doi.org/10.1175/1520-0434 (1994)009<0209:ASHIPS>2.0.CO;2.

— Prediction Scheme (SHIPS) for the Atlantic and eastern North Pacific basins. Wea. Forecasting, 14, 326-337, https:// doi.org/10.1175/1520-0434(1999)014<0326:AUSHIP >2.0. $\mathrm{CO} ; 2$.

_ , M. Mainelli, L. K. Shay, J. A. Knaff, and J. Kaplan, 2005: Further improvements to the Statistical Hurricane Intensity Prediction Scheme (SHIPS). Wea. Forecasting, 20, 531-543, https://doi.org/10.1175/WAF862.1.

—, R. T. DeMaria, J. A. Knaff, and D. Molenar, 2012: Tropical cyclone lightning and rapid intensity change. Mon. Wea. Rev., 140, 1828-1842, https://doi.org/10.1175/MWR-D-1100236.1

— C. R. Sampson, J. A. Knaff, and K. D. Musgrave, 2014: Is tropical cyclone intensity guidance improving? Bull. Amer. Meteor. Soc., 95, 387-398, https://doi.org/10.1175/BAMS-D12-00240.1.

Fierro, A. O., and J. M. Reisner, 2011: High-resolution simulation of the electrification and lightning of Hurricane Rita during the period of rapid intensification. J. Atmos. Sci., 68, 477-494, https://doi.org/10.1175/2010JAS3659.1.

_ , and E. R. Mansell, 2017: Electrification and lightning in idealized simulations of a hurricane-like vortex subject to wind shear and sea surface temperature cooling. J. Atmos. Sci., 74, 2023-2041, https://doi.org/10.1175/JAS-D-16-0270.1.

$\longrightarrow$, and - 2018: Relationships between electrification and storm-scale properties based on idealized simulations of an intensifying hurricane-like vortex. J. Atmos. Sci., 75, 657-674, https://doi.org/10.1175/JAS-D-17-0202.1.

_ , M. S. Gilmore, E. R. Mansell, L. J. Wicker, and J. M. Straka, 2006: Electrification and lightning in an idealized boundarycrossing supercell simulation of 2 June 1995. Mon. Wea. Rev., 134, 3149-3172, https://doi.org/10.1175/MWR3231.1.

_ L. M. Leslie, E. R. Mansell, J. M. Straka, D. R. MacGorman, and C. Ziegler, 2007: A high-resolution simulation of the microphysics and electrification in an idealized hurricane-like vortex. Meteor. Atmos. Phys., 98, 13-33, https://doi.org/ 10.1007/s00703-006-0237-0.

_ X.-M. Shao, T. Hamlin, J. M. Reisner, and J. D. Harlin, 2011: Evolution of eyewall convective events as indicated by intracloud and cloud-to-ground lightning activity during the rapid intensification of Hurricanes Rita and Katrina. Mon. Wea. Rev., 139, 1492-1504, https://doi.org/10.1175/ 2010MWR3532.1. 
,E. R. Mansell, D. R. MacGorman, and C. Ziegler, 2013: The implementation of an explicit charging and discharge lightning scheme within the WRF-ARW Model: Benchmark simulations with a continental squall line, a tropical cyclone, and a winter storm. Mon. Wea. Rev., 141, 2390-2415, https://doi.org/ 10.1175/MWR-D-12-00278.1.

,-- , C. Ziegler, and D. R. MacGorman, 2015: Explicitly simulated electrification and lightning within a tropical cyclone based on the environment of Hurricane Isaac (2012). J. Atmos. Sci., 72, 4167-4193, https://doi.org/10.1175/JAS-D-14-0374.1.

Fuchs, B. R., E. C. Bruning, S. A. Rutledge, L. D. Carey, P. R. Krehbiel, and W. Rison, 2016: Climatological analyses of LMA data with an open-source lightning flash-clustering algorithm. J. Geophys. Res. Atmos., 121, 8625-8648, https://doi.org/10.1002/2015JD024663.

Goodman, S. J., D. E. Buechler, P. D. Wright, and W. D. Rust, 1988: Lightning and precipitation history of a microburstproducing storm. Geophys. Res. Lett., 15, 1185-1188, https:// doi.org/10.1029/GL015i011p01185.

_ , and Coauthors, 2005: The North Alabama Lightning Mapping Array: Recent severe storm observations and future prospects. Atmos. Res., 76, 423-437, https://doi.org/10.1016/ j.atmosres.2004.11.035.

— , and Coauthors, 2013: The GOES-R Geostationary Lightning Mapper (GLM). Atmos. Res., 125-126, 34-49, https://doi.org/ 10.1016/j.atmosres.2013.01.006.

Guimond, S. R., G. M. Heymsfield, and F. J. Turk, 2010: Multiscale observations of Hurricane Dennis (2005): The effects of hot towers on rapid intensification. J. Atmos. Sci., 67, 633-654, https://doi.org/10.1175/2009JAS3119.1.

Gurka, J. J., T. A. Schmit, T. M. Renkevens, M. M. Gunshor, and J. Li, 2006: 2006 update on baseline instruments for GOES-R series. Proc. Atmospheric and Environmental Remote Sensing Data Processing and Utilization II: Perspective on Calibration/ Validation Initiatives and Strategies, San Diego, CA, International Society for Optical Engineering, $63010 \mathrm{H}$, https://doi. org/10.1117/12.683701.

Hazelton, A. T., R. E. Hart, and R. F. Rogers, 2017: Analyzing simulated convective bursts in two Atlantic hurricanes. Part II: Intensity change due to bursts. Mon. Wea. Rev., 145, 30953117, https://doi.org/10.1175/MWR-D-16-0268.1.

Hendricks, E. A., M. T. Montgomery, and C. A. Davis, 2004: The role of "vortical" hot towers in the formation of Tropical Cyclone Diana (1984). J. Atmos. Sci., 61, 1209-1232, https://doi.org/ 10.1175/1520-0469(2004)061<1209:TROVHT>2.0.CO;2.

Holle, R. L., K. L. Cummins, and W. A. Brooks, 2016: Seasonal, monthly, and weekly distributions of NLDN and GLD360 cloud-to-ground lightning. Mon. Wea. Rev., 144, 2855-2870, https://doi.org/10.1175/MWR-D-16-0051.1.

Jacobson, A. R., R. Holzworth, J. Harlin, R. Dowden, and E. Lay, 2006: Performance assessment of the World Wide Lightning Location Network (WWLLN), using the Los Alamos Sferic Array (LASA) as ground truth. J. Atmos. Oceanic Technol., 23, 1082-1092, https://doi.org/10.1175/JTECH1902.1.

Kaplan, J., M. DeMaria, and J. A. Knaff, 2010: A revised tropical cyclone rapid intensification index for the Atlantic and eastern North Pacific basins. Wea. Forecasting, 25, 220-241, https://doi.org/10.1175/2009WAF2222280.1.

_- and Coauthors, 2015: Evaluating environmental impacts on tropical cyclone rapid intensification predictability utilizing statistical models. Wea. Forecasting, 30, 1374-1396, https:// doi.org/10.1175/WAF-D-15-0032.1.

Kelley, O. A., J. Stout, and J. B. Halverson, 2004: Tall precipitation cells in tropical cyclone eyewalls are associated with tropical cyclone intensification. Geophys. Res. Lett., 31, L24112, https://doi.org/10.1029/2004GL021616.

Knaff, J. A., M. DeMaria, C. R. Sampson, J. E. Peak, J. Cummings, and W. H. Schubert, 2013: Upper oceanic energy response to tropical cyclone passage. J. Climate, 26, 2631-2650, https:// doi.org/10.1175/JCLI-D-12-00038.1.

Koshak, W. J., and Coauthors, 2004: North Alabama Lightning Mapping Array (LMA): VHF source retrieval algorithm and error analyses. J. Atmos. Oceanic Technol., 21, 543-558, https:// doi.org/10.1175/1520-0426(2004)021<0543:NALMAL > 2.0.CO;2.

Kossin, J. P., 2015: Hurricane wind-pressure relationship and eyewall replacement cycles. Wea. Forecasting, 30, 177-181, https://doi.org/10.1175/WAF-D-14-00121.1.

— and M. Sitkowski, 2012: Predicting hurricane intensity and structure changes associated with eyewall replacement cycles. Wea. Forecasting, 27, 484-488, https://doi.org/10.1175/WAFD-11-00106.1.

Kuhlman, K. M., C. L. Ziegler, E. R. Mansell, D. R. MacGorman, and J. M. Straka, 2006: Numerically simulated electrification and lightning of the 29 June 2000 STEPS supercell storm. Mon. Wea. Rev., 134, 2734-2757, https://doi.org/10.1175/MWR3217.1.

Lang, T. J., and S. A. Rutledge, 2002: Relationships between convective storm kinematics, precipitation, and lightning. Mon. Wea. Rev., 130, 2492-2506, https://doi.org/10.1175/15200493(2002) $130<2492:$ RBCSKP $>2.0$. CO;2.

Liu, C., and S. Heckman, 2012: Total lightning data and real-time severe storm prediction. TECO-2012: WMO Tech. Conf. on Meteorological and Environmental Instruments and Methods of Observation, Brussels, Belgium, World Meteorological Organization, P5(10). http://www.wmo.int/pages/prog/www/ IMOP/publications/IOM-109_TECO-2012/Session5/P5_10_ Liu_Total_Lightning_Data_and_Real-Time_Severe_Storm_ Prediction.pdf.

Lyons, W. A., M. G. Venne, P. G. Black, and R. C. Gentry, 1989: Hurricane lightning: A new diagnostic tool for tropical storm forecasting? Preprints, 18th Conf. on Hurricanes and Tropical Meteorology, San Diego, CA, Amer. Meteor. Soc., 2 pp.

MacGorman, D. R., and W. D. Rust, 1998: The Electrical Nature of Storms. Oxford University Press, $422 \mathrm{pp}$.

- D. W. Burgess, V. Mazur, W. D. Rust, W. L. Taylor, and B. C. Johnson, 1989: Lightning rates relative to tornadic storm evolution on 22 May 1981. J. Atmos. Sci., 46, 221-251, https://doi.org/ 10.1175/1520-0469(1989)046<0221:LRRTTS>2.0.CO;2.

Mach, D. M., H. J. Christian, R. J. Blakeslee, D. J. Boccippio, S. J. Goodman, and W. L. Boeck, 2007: Performance assessment of the Optical Transient Detector and Lightning Imaging Sensor. J. Geophys. Res., 112, D09210, https://doi.org/10.1029/ $2006 J D 007787$.

Marks, F. D., and Coauthors, 1998: Landfalling tropical cyclones: Forecast problems and associated research opportunities. Bull. Amer. Meteor. Soc., 79, 305-323.

Medici, G., K. L. Cummins, D. J. Cecil, W. J. Koshak, and S. D. Rudlosky, 2017: The intracloud lightning fraction in the contiguous United States. Mon. Wea. Rev., 145, 4481-4499, https://doi.org/10.1175/MWR-D-16-0426.1.

Molinari, J., P. K. Moore, V. P. Idone, R. W. Henderson, and A. B. Saljoughy, 1994: Cloud-to-ground lightning in Hurricane Andrew. J. Geophys. Res., 99, 16 665-16676, https://doi.org/ 10.1029/94JD00722.

- — - and - -1999 : Convective structure of hurricanes as revealed by lightning locations. Mon. Wea. Rev., 127, 520-534, https://doi.org/10.1175/1520-0493(1999)127<0520: CSOHAR $>2.0 . \mathrm{CO} ; 2$. 
Montgomery, M. T., M. E. Nicholls, T. A. Cram, and A. B. Saunders, 2006: A vortical hot tower route to tropical cyclogenesis. J. Atmos. Sci., 63, 355-386, https://doi.org/10.1175/JAS3604.1.

Nolan, D. S., Y. Moon, and D. P. Stern, 2007: Tropical cyclone intensification from asymmetric convection: Energetics and efficiency. J. Atmos. Sci., 64, 3377-3405, https://doi.org/ 10.1175/JAS3988.1.

Orville, R. E., and J. M. Coyne, 1999: Cloud-to-ground lightning in tropical cyclones (1986-1996). Preprints, 23rd Conf. on Hurricanes and Tropical Meteorology, Dallas, TX, Amer. Meteor. Soc., 4A.12, https://ams.confex.com/ams/99annual/abstracts/1695.htm.

Rakov, V. A., 2016: Fundamentals of Lightning. Cambridge University Press, $257 \mathrm{pp}$.

Reynolds, R. W., and T. M. Smith, 1994: Improved global sea surface temperature analyses using optimum interpolation. J. Climate, 7, 929-948, https://doi.org/10.1175/1520-0442(1994) 007<0929:IGSSTA > 2.0.CO;2.

,-- C. C. Liu, D. B. Chelton, K. S. Casey, and M. G. Schlax, 2007: Daily high-resolution-blended analyses for sea surface temperature. J. Climate, 20, 5473-5496, https://doi.org/ 10.1175/2007JCLI1824.1.

Rison, W., R. J. Thomas, P. R. Krehbiel, T. Hamlin, and J. Harlin, 1999: A GPS-based three-dimensional lightning mapping system: Initial observations in central New Mexico. Geophys. Res. Lett., 26, 3573-3576, https://doi.org/10.1029/1999GL010856.

Rogers, R., P. Reasor, and S. Lorsolo, 2013: Airborne Doppler observations of the inner-core structural differences between intensifying and steady-state tropical cyclones. Mon. Wea. Rev., 141, 2970-2991, https://doi.org/10.1175/MWR-D-12-00357.1.

Said, R. K., U. S. Inan, and K. L. Cummins, 2010: Long-range lightning geolocation using a VLF radio atmospheric waveform bank. J. Geophys. Res., 115, D23108, https://doi.org/ 10.1029/2010JD013863.

Samsury, C. E., and R. E. Orville, 1994: Cloud-to-ground lightning in tropical cyclones: A study of Hurricanes Hugo (1989) and Jerry (1989). Mon. Wea. Rev., 122, 1887-1896, https://doi.org/ 10.1175/1520-0493(1994)122<1887:CTGLIT>2.0.CO;2.

Saunders, C. P. R., and S. L. Peck, 1998: Laboratory studies of the influence of the rime accretion rate on charge transfer during crystal/graupel collisions. J. Geophys. Res., 103, 13 949-13 956, https://doi.org/10.1029/97JD02644.

$\longrightarrow,-$ G. G. Aguirre Varela, E. E. Avila, and N. E. Castellano, 2001: A laboratory study of the influence of water vapour and mixing on the charge transfer process during collisions between ice crystal and graupel. Atmos. Res., 58, 187-203, https:// doi.org/10.1016/S0169-8095(01)00090-4.

Schubert, W. H., and J. J. Hack, 1982: Inertial stability and tropical cyclone development. J. Atmos. Sci., 39, 1687-1697, https://doi. org/10.1175/1520-0469(1982)039<1687:ISATCD>2.0.CO;2.

Schultz, C. J., W. A. Petersen, and L. D. Carey, 2011: Lightning and severe weather: A comparison between total and cloud-toground lightning trends. Wea. Forecasting, 26, 744-755, https:// doi.org/10.1175/WAF-D-10-05026.1.

Shao, X. M., and Coauthors, 2005: Katrina and Rita were lit up with lightning. Eos, Trans. Amer. Geophys. Union, 86, 398, https:// doi.org/10.1029/2005EO420004.

Shapiro, L. J., 1983: The asymmetric boundary layer flow under a translating hurricane. J. Atmos. Sci., 40, 1984-1998, https:// doi.org/10.1175/1520-0469(1983)040<1984:TABLFU>2.0.CO;2.

_- and J. L. Franklin, 1999: Potential vorticity asymmetries and tropical cyclone motion. Mon. Wea. Rev., 127, 124-131, https:// doi.org/10.1175/1520-0493(1999)127<0124:PVAATC $>2.0$. $\mathrm{CO} ; 2$.
Sitkowski, M., J. P. Kossin, and C. M. Rozoff, 2011: Intensity and structure changes during hurricane eyewall replacement cycles. Mon. Wea. Rev., 139, 3829-3847, https://doi.org/10.1175/ MWR-D-11-00034.1.

$\longrightarrow,-\longrightarrow$, , and J. Knaff, 2012: Hurricane eyewall replacement cycles and the relict inner eyewall circulation. Mon. Wea. Rev., 140, 4035-4045, https://doi.org/10.1175/MWR-D11-00349.1.

Skamarock, W. C., and J. B. Klemp, 2008: A time-split nonhydrostatic atmospheric model for research and forecasting applications. J. Comput. Phys., 227, 3465-3485, https://doi.org/ 10.1016/j.jcp.2007.01.037.

Smith, R. K., and M. T. Montgomery, 2015: Toward clarity on understanding tropical cyclone intensification. J. Atmos. Sci., 72, 3020-3031, https://doi.org/10.1175/JAS-D-15-0017.1.

Squires, K., and S. Businger, 2008: The morphology of eyewall lightning outbreaks in two category 5 hurricanes. Mon. Wea. Rev., 136, 1706-1726, https://doi.org/10.1175/ 2007MWR2150.1.

Stevenson, S. N., K. L. Corbosiero, and S. F. Abarca, 2016: Lightning in eastern North Pacific tropical cyclones: A comparison to the North Atlantic. Mon. Wea. Rev., 144, 225-239, https:// doi.org/10.1175/MWR-D-15-0276.1.

, M. DeMaria, and J. L. Vigh, 2018: A 10-year survey of tropical cyclone inner-core lightning bursts and their relationship to intensity change. Wea. Forecasting, 33, 23-36, https://doi.org/10.1175/WAF-D-17-0096.1.

Thomas, J. N., N. Solorzano, S. A. Cummer, and R. H. Holzworth, 2010: Polarity and energetics of inner core lightning in three intense North Atlantic hurricanes. J. Geophys. Res., 115, A00E15, https://doi.org/10.1029/2009JA014777.

Uhlhorn, E. W., and P. G. Black, 2003: Verification of remotely sensed sea surface winds in hurricanes. J. Atmos. Oceanic Technol., 20, 99-116, https://doi.org/10.1175/1520-0426(2003) $020<0099$ :VORSSS $>2.0$. CO;2.

Wadler, J. B., R. F. Rogers, and P. D. Reasor, 2018: The relationship between spatial variations in the structure of convective bursts and tropical cyclone intensification as determined by airborne Doppler radar. Mon. Wea. Rev., 146, 761-780, https://doi.org/10.1175/MWR-D-17-0213.1.

Wiens, K. C., S. A. Rutledge, and S. A. Tessendorf, 2005: The 29 June 2000 supercell observed during STEPS. Part II: Lightning and charge structure. J. Atmos. Sci., 62, 4151-4177, https://doi.org/10.1175/JAS3615.1.

Williams, E., and N. Renno, 1993: An analysis of the conditional instability of the tropical atmosphere. Mon. Wea Rev., 121, 21-36, https://doi.org/10.1175/1520-0493(1993) $121<0021$ :AAOTCI $>2.0$.CO;2.

Willoughby, H. E., J. A. Clos, and M. Shoreibah, 1982: Concentric eye walls, secondary wind maxima, and the evolution of the hurricane vortex. J. Atmos. Sci., 39, 395-411, https://doi.org/ 10.1175/1520-0469(1982)039<0395:CEWSWM>2.0.CO;2.

Xu, W., S. A. Rutledge, and W. Zhang, 2017: Relationships between total lightning, deep convection, and tropical cyclone intensity change. J. Geophys. Res. Atmos., 122, 7047-7063, https://doi.org/10.1002/2017JD027072.

Yoshida, S., T. Morimoto, T. Ushio, and Z. Kawasaki, 2009: A fifthpower relationship for lightning activity from Tropical Rainfall Measuring Mission satellite observations. J. Geophys. Res., 114, D09104, https://doi.org/10.1029/2008JD010370.

Zhang, F., and J. A. Sippel, 2009: Effects of moist convection on hurricane predictability. J. Atmos. Sci., 66, 1944-1961, https:// doi.org/10.1175/2009JAS2824.1. 